\title{
Crtcl Activates a Transcriptional Program Deregulated at Early Alzheimer's Disease-Related Stages
}

\author{
Arnaldo Parra-Damas, ${ }^{1,2 \star}$ Jorge Valero, ${ }^{1,2 \star}$ Meng Chen, ${ }^{1,2}$ Judit España, ${ }^{1,2}$ Elsa Martín, ${ }^{1,2}$ Isidro Ferrer, ${ }^{2,3}$ \\ José Rodríguez-Alvarez, ${ }^{1,2}$ and Carlos A. Saura ${ }^{1,2}$ \\ ${ }^{1}$ Institut de Neurociències, Department de Bioquímica i Biologia Molecular, Universitat Autònoma de Barcelona, Barcelona 08193, Spain, and ${ }^{2}$ Centro de \\ Investigación Biomédica en Red Enfermedades Neurodegenerativas (CIBERNED) and 3 Institut de Neuropatologia, IDIBELL-Hospital Universitari de \\ Bellvitge, Universitat de Barcelona, Barcelona 08907, Spain
}

Cognitive decline is associated with gene expression changes in the brain, but the transcriptional mechanisms underlying memory impairments in cognitive disorders, such as Alzheimer's disease (AD), are largely unknown. Here, we aimed to elucidate relevant mechanisms responsible for transcriptional changes underlying early memory loss in AD by examining pathological, behavioral, and transcriptomic changes in control and mutant $\beta$-amyloid precursor protein $\left(\mathrm{APP}_{\mathrm{Sw}_{\text {Ind }}}\right)$ transgenic mice during aging. Genome-wide transcriptome analysis using mouse microarrays revealed deregulation of a gene network related with neurotransmission, synaptic plasticity, and learning/memory in the hippocampus of $A P P_{S w, I n d}$ mice after spatial memory training. Specifically, $A P P_{S w, I n d}$ mice show changes on a cAMP-responsive element binding protein (CREB)regulated transcriptional program dependent on the CREB-regulated transcription coactivator-1 (Crtc1). Interestingly, synaptic activity and spatial memory induces Crtcl dephosphorylation (Ser151), nuclear translocation, and Crtc1-dependent transcription in the hippocampus, and these events are impaired in $\mathrm{APP}_{\mathrm{S} \text {,Ind }}$ mice at early pathological and cognitive decline stages. CRTC1-dependent genes and CRTC1 levels are reduced in human hippocampus at intermediate Braak III/IV pathological stages. Importantly, adeno-associated viral-mediated Crtcl overexpression in the hippocampus efficiently reverses $\mathrm{A} \beta$-induced spatial learning and memory deficits by restoring a specific subset of $\mathrm{Crtc1}$ target genes. Our results reveal a critical role of Crtc1-dependent transcription on spatial memory formation and provide the first evidence that targeting brain transcriptome reverses memory loss in $\mathrm{AD}$.

Key words: $\beta$-amyloid; CREB; gene expression; memory; neurodegeneration; TORC

\section{Introduction}

Alzheimer's disease (AD), the most common cause of dementia, is characterized pathologically by abnormal accumulation of $\beta$-amyloid (A $\beta$ ) peptides, hyperphosphorylated tau and synapse dysfunction in the brain. The earliest cognitive symptoms of the disease are temporally associated with progression of tau and amyloid pathologies from the entorhinal cortex and hippocam-

Received Dec. 18, 2013; revised Feb. 5, 2014; accepted March 17, 2014.

Author contributions: A.P.-D., J.V., M.C., J.E., I.F., J.R.-A., and C.A.S. designed research; A.P.-D., J.V., M.C., J.E., E.M., and C.A.S. performed research; I.F. and J.R.-A. contributed unpublished reagents/analytic tools; A.P.-D., J.V., M.C., J.E., and E.M. analyzed data; C.A.S. wrote the paper.

This work was supported by grants from the Ministerio de Economia y Competitividad (SAF2010-20925 and CIBERNED (B06/05/0042), and the European Commission (MEMOSAD project, FP7-200611). A.P.-D and M.C. are supported by doctoral fellowships from Ministerio de Ciencia e Innovación (BES-2011-044405) and China Scholarship Council, respectively. We thank L. Mucke for providing the APP ${ }_{S_{w} \text {, Ind }}$ mice and J.-R. Cardinaux for mouse Crtc1 plasmid, Mar Castillo and Núria Barba from the Institut de Neurociències Histology and Microscope Units for technical assistance, the Servei de Genòmica Bioinformàtica-IBB-UAB, the Unitat de Producció de Vectors Virals (UPVV)-UAB for generating the AAV vectors, and S. Ginés for critical comments of the paper, and the Fundación CIEN (Instituto de Salud Carlos III, Spain) for human brain samples.

The authors declare no competing financial interests.

${ }^{*}$ A.P. -D. and J.V. contributed equally to this work.

Correspondence should be addressed to Dr Carlos A. Saura, Institut de Neurociències, Facultat de Medicina M2-113, Universitat Autònoma de Barcelona, Bellaterra (Barcelona), Spain 08193. E-mail: carlos.saura@uab.es.

J. Valero's present address: Center for Neuroscience and Cell Biology, Universidade de Coimbra, 3004-504 Coimbra, Portugal.

DOI:10.1523/JNEUROSCI.5288-13.2014

Copyright $\odot 2014$ the authors $\quad 0270-6474 / 14 / 345776-12 \$ 15.00 / 0$ pus to associative and temporal cortical areas (Braak et al., 2006). Memory impairments in AD transgenic mouse models are evident before accumulation of amyloid plaques (Oddo et al., 2003; Saura et al., 2005) suggesting that events downstream of $A \beta$ contribute to synaptic changes early in the disease process. Among these events, transcriptome changes affecting cell signaling, metabolic, inflammation and neurotransmission pathways precede neuropathology in AD brains (Blalock et al., 2004; Bossers et al., 2010; Twine et al., 2011). This raises the possibility that deregulation of mechanisms controlling brain transcriptome may underlie memory loss at early AD stages.

Activity-dependent gene transcription is essential for longlasting plastic changes in neuronal circuits encoding memory. cAMP-responsive element binding protein (CREB)-dependent transcription, which mediates neuronal excitability, synaptic plasticity, and long-lasting memory in the hippocampus (Lee and Silva, 2009), depends on the transcriptional coactivator CRTC1 (or mouse Crtc1) (Conkright et al., 2003b). In response to synaptic activity, Crtcl translocates from the cytosol to the nucleus to increase CREB binding to specific gene promoters (Altarejos et al., 2008; España et al., 2010b; Ch'ng et al., 2012). Recent evidences suggest that $\mathrm{A} \beta$ negatively affect hippocampal synaptic plasticity, memory and synapse loss by deregulating cAMP/Ca ${ }^{2+}$-mediated CREB signaling (Vitolo et al., 2002; Smith et al., 2009; España et al., 2010b). Consistently, CREB-signaling activation ameliorates learn- 
ing and/or memory deficits in transgenic $\mathrm{AD}$ mouse models (Gong et al., 2004; Caccamo et al., 2010; Yiu et al., 2011). These results suggest that disruption of CREB signaling may contribute to memory deficits in $\mathrm{AD}$ (Saura and Valero, 2011), but the specific CREBdependent gene programs that mediate early synaptic dysfunction and memory loss in $\mathrm{AD}$ are unknown. A better understanding of these mechanisms is crucial for elucidating new signaling pathways for drug discovery in cognitive disorders.

To investigate the molecular mechanisms responsible for transcriptome changes during the progression of $\mathrm{AD}$, we performed extensive pathological, behavioral, transcriptional, and biochemical analyses in WT and APP transgenic mice at 2-18 months of age (Mucke et al., 2000). Genome-wide transcriptome analyses were performed in naive and memory trained $\mathrm{APP}_{\mathrm{Sw}_{\mathrm{w}} \text { Ind }}$ transgenic mice at initial pathological and cognitive decline stages. Microarray and bioinformatic enrichment analyses revealed a set of CREB-dependent genes involved in synaptic function and plasticity deregulated in the hippocampus of $\mathrm{APP}_{\mathrm{Sw}, \text { Ind }}$ transgenic mice specifically after memory training. These transcriptional changes were associated with Crtc1 dysfunction but not CREB changes. Crtcl overexpression in the hippocampus efficiently reversed transcriptome and spatial learning and memory deficits in $\mathrm{APP}_{\mathrm{Sw}, \text { Ind }}$ mice, suggesting that enhancing Crtc1 function may provide therapeutic benefits for transcriptome and memory deficits at early AD stages.

\section{Materials and Methods}

Transgenic mice and human samples. $\mathrm{APP}_{\mathrm{Sw}, \mathrm{Ind}}$ transgenic mice (line J9) expressing human $\mathrm{APP}_{695}$ harboring the FAD-linked Swedish (K670N/ M671L) and Indiana (V717F) mutations under the neuronal PDGF $\beta$ promoter were obtained by crossing $\mathrm{APP}_{\mathrm{Sw}, \text { Ind }}$ to nontransgenic (WT) mice. Mice used in this study were age-matched male littermate control and $\mathrm{APP}_{\mathrm{Sw}, \text { Ind }}$ mice (C57BL/6 background). Human brain samples were obtained from brain banks of Hospital de Bellvitge (Universitat de Barcelona, Spain) and Fundación CIEN (Instituto de Salud Carlos III, Spain). Brains samples were matched as closely as possible for sex, age and postmortem interval. Neuropathology was classified according to Braak staging for neurofibrillary tangles and neuritic plaques (Braak et al., 2006). Experimental procedures were conducted according to the Animal and Human Ethical Committee of the Universitat Autònoma de Barcelona (protocol CEEAH 1783, Generalitat Catalunya 6381) following the European Union guidelines.

Viral constructs and transcriptional assays. Lentiviral Crtcl shRNAs were generated by transfecting pLVTHM containing mouse Crtcl or scramble ShRNA, pSPAX2 and pM2G vectors in HEK293T cells as described previously (España et al., 2010b). Adeno-associated virus (AAV) AAV2/10-Crtc1-myc containing the AAV2 genome into AAV10 packing vectors and under the chicken $\beta$-actin promoter was generated by subcloning pcDNA3-Crtcl-myc (Kovács et al., 2007) into pVAX1 (Invitrogene) and pGV-IRES2-GFP vectors. AAV were generated by transfecting HEK293T cells with AAV2 recombinant, pRepAAV2/CapAAV10, and pXX6 vectors. For transcriptional assays, hippocampal neurons were infected at 3 DIV with scramble or Crtc1 shRNA lentivirus (2 transducing units/cell) or AAV2/10-Crtc1 or AAV2/10-GFP virus $\left(1 \times 10^{5} \mathrm{gc} /\right.$ cell $)$. Neurons (10 DIV) were transfected with pCRE-luc ( $0.5 \mu \mathrm{g}$; Stratagene) and TK renilla (0.25 $\mu \mathrm{g}$; Promega) plasmids using LipofectAMINE 2000 for $24 \mathrm{~h}$ before stimulation (FSK/KCl) for $4 \mathrm{~h}$ and analyzed with the dual-luciferase activity assay (Promega) in a Synergy HT luminometer (Bio-Tek; España et al., 2010b).

ChIP analysis. Chromatin immunoprecipitation (ChIP) was performed as described previously (Dahl and Collas, 2008; España et al., 2010b). Neurons (12-14 DIV) were treated with vehicle or FSK $(20 \mu \mathrm{M})$ and $\mathrm{KCl}(30 \mathrm{~mm})$ for $30 \mathrm{~min}$. Cells were crosslinked with $1 \%$ formaldehyde, lysed in ChIP buffer (50 mm Tris-HCl, pH 8.1, 100 mm NaCl, 5 mm EDTA, $1 \%$ SDS, $0,1 \%$ Na deoxycholate, and protease/phosphatase inhibitors) and sonicated. DNA $(2.5 \mu \mathrm{g})$ immunoprecipitations were per- formed overnight in diluted ChIP buffer (0.1\% SDS, $1.1 \%$ Triton X-100) with rabbit CRTC1 and CREB antibodies or irrelevant IgGs (Cell Signaling Technology). Immunoprecipitated DNA was decrosslinked and amplified by real-time PCR using specific primers for CRE-containing promoter sequences of specific genes.

Behavioral studies and viral injections. The Morris water maze (MWM) was performed in $3 \mathrm{~d}$ handled mice in a circular pool $(90 \mathrm{~cm}$ diameter; 6.5 $\mathrm{cm}$ hidden platform) for three or five consecutive days (4 trials daily; $60 \mathrm{~s}$ per trial; España et al., 2010a). Mice were tested for memory retention (probe trial) $2.5 \mathrm{~h}$ after training on day five, and they were killed $30 \mathrm{~min}$ after training. We selected this time to get a measure of memory retention while achieving a maximum peak of gene expression, which occurs $\sim 0.5-2 \mathrm{~h}$ after spatial training (Guzowski et al., 2001). The swimming group moved freely in the maze without platform for $5 \mathrm{~d}$ and mice were killed $30 \mathrm{~min}$ after a simulated probe trial. For viral injections, 6-monthold mice ( $n=8 \mathrm{mice} /$ group) were anesthetized with isofluorane and placed in a stereotaxic platform (Kopf). The injection coordinates for the hippocampus were as follows: anterior 0.2 caudal to bregma; 0.18 lateral to bregma; depth 0.2 ventral to dural surface. AAV2/10-GFP or -Crtc1 viral stocks ( $3 \mu \mathrm{l} ; 5.1 \times 10^{11} \mathrm{gc} / \mathrm{ml} ; 0.5 \mu \mathrm{l} / \mathrm{min}$ ) were injected bilaterally into the hippocampus. Three weeks after AAV injection mice were tested in the water maze $(120 \mathrm{~cm}$ circular pool; $11 \mathrm{~cm}$ platform) for $5 \mathrm{~d}$ (6 trials daily; $60 \mathrm{~s}$ per trial), tested in a probe trial $2.5 \mathrm{~h}$ after training, killed, and dissected. Importantly, both maze setups lead to similar values of escape latencies during spatial training and memory retention in the probe trial test in $\mathrm{WT}$ and $\mathrm{APP}_{\mathrm{Sw}, \text { Ind }}$ mice (compare Figs. $1 C, 4 D$ ). In all cases, spatial learning and memory parameters were analyzed with SMART software (PanLab; España et al., 2010a).

Biochemical analysis. For biochemical analysis, naive and trained mice were killed $30 \mathrm{~min}$ after training by cervical dislocation and whole hippocampus dissected out and immediately frozen. Tissue was lysed in cold-lysis buffer (50 mм Tris- $\mathrm{HCl}, \mathrm{pH}$ 7.4, $150 \mathrm{~mm} \mathrm{NaCl}, 2$ mм EDTA, $0.5 \%$ Triton X-100, $1 \%$ NP-40, 0.1\% SDS, $1 \mathrm{~mm} \mathrm{Na}_{3} \mathrm{VO}_{4}, 50 \mathrm{~mm} \mathrm{NaF}, 1$ mM PMSF) containing protease and phosphatase inhibitors (Roche). For nuclear fractionation mouse forebrains were freshly dissected, gently homogenized in ice-cold sucrose buffer A (10 mM HEPES, pH 7.5, $200 \mathrm{~mm}$ sucrose, $1.5 \mathrm{~mm} \mathrm{MgCl}_{2}, 10 \mathrm{~mm} \mathrm{KCl}$, protease/phosphatase inhibitors) and centrifuged $(1500 \times g, 15 \mathrm{~min})$. The pellet was homogenized in $1.6 \mathrm{M}$ sucrose buffer, fractionated in 2.2-1.4 M sucrose gradients $(100,000 \times g, 35$ $\left.\mathrm{min}, 4^{\circ} \mathrm{C}\right)$ and the pellet (nuclei) was lysed in buffer B $(25 \mathrm{~mm}$ Tris- $\mathrm{HCl}, \mathrm{pH}$ 7.4, $150 \mathrm{~mm} \mathrm{NaCl}, 1 \% \mathrm{NP}-40$, and $10 \%$ glycerol as described previously (Thormodsson et al., 1995; Saura et al., 2004). Proteins were quantified with the BCA protein assay kit (Pierce) and resolved by SDS-PAGE and Western blotting. Protein bands were quantified with the ImageJ software within a linear range of detection. The following antibodies were used: rabbit antiCrtc1, CREB, phosphorylated CREB (Ser133), and Nur77 (Cell Signaling Technology); phosphorylated CRTC1 (Ser151; España et al., 2010b); CBP (A-22), BDNF, c-fos (4), rabbit c-myc (A-10), and c-myc (9E10) (Santa Cruz Biotechnology); rabbit APP C-terminal antibody (Saeko; aa 665-695); rabbit $\alpha$ APPs antibody (1736; aa 595-611) recognizing specifically cleaved $\alpha$ APPs C-terminus; Nurr1, GAPDH, $\beta$-tubulin and $\alpha$-actin) (AC15) from Abcam, and lamin B1 (Zymed).

Immunohistochemical and immunofluorescence staining. For A $\beta$ staining, sagittal brain paraffin sections $(5 \mu \mathrm{m})$ were deparaffinized in xylene, rehydrated, and incubated with $3 \%$ hydrogen peroxide as described previously (España et al., 2010a). Sections were incubated in 60\% formic acid for 6 min to allow antigen retrieval, washed in $0.1 \mathrm{M}$ Tris- $\mathrm{HCl}$, and incubated with anti-A $\beta(6 \mathrm{E} 10 ; 1: 1000$; Signet) before immunoperoxidase staining and analysis with a Nikon Eclipse 90i microscope. This staining protocol was previously shown to label specifically A $\beta$ in APP transgenic mice (España et al., 2010a). For Crtc1-myc and Arc staining, floating sections $(40 \mu \mathrm{m})$ were blocked in PBS containing $5 \%$ normal goat serum and $0.2 \%$ Triton X-100 and incubated with rabbit anti-myc (1:1000) and mouse anti-NeuN (1:2000; Millipore) antibodies or rabbit anti-Crtc1 (1:300) and mouse anti-myc (1:500; 9E10) or anti-Arc (1:100; Ab62142, Abcam) and the Alexa Fluor 488/594-conjugated goat secondary antibodies (1:400; Invitrogen) and Hoechst (1:10,000; Invitrogen). For Crtc1 nuclear translocation analysis, mice were trained in the MWM for $5 \mathrm{~d}$ and killed $30 \mathrm{~min}$ after training. Mice were deeply anesthetized 
with pentobarbital (200 mg/kg, i.p.) and intracardially perfused with saline and $4 \%$ buffered formaldehyde. Paraffin sections $(5 \mu \mathrm{m})$ were deparaffinized, microwave heated (10 $\mathrm{min})$ in antigen retrieval citrate buffer and incubated with CRTC1 (1:300; Cell Signaling Technology) and MAP2 (1:300; SigmaAldrich) antibodies and Hoechst followed by AlexaFluor 488/594-conjugated goat IgGs. Images $(20 \times$; zoom 0.5$)$ of hippocampal subregions (4 sections; $n=5-6 /$ group) were obtained with a Zeiss LSM700 laser scanning microscope. Crtcl nuclear staining intensity in the selected regions was measured using a sum projection of six Z-sections ( $1 \mu \mathrm{m}) /$ section). Hoechst labeling was used to assign the region of interest for nuclear Crtcl staining, whereas 2 $\mu \mathrm{m}$ area around the nucleus was considered cytoplasmic. Crtcl nuclear/cytoplasm intensity ratio was calculated using ImageJ software (v1.47n).

Microarray and bioinformatic analyses. For microarray analyses, nontransgenic control (WT) and $\mathrm{APP}_{\mathrm{Sw}, \text { Ind }}$ mice $(n=3-4$ /group) were handled and kept in the home cage (naive) or trained in the MWM for five consecutive days and tested in a probe trial $2.5 \mathrm{~h}$ later. Trained mice were killed $30 \mathrm{~min}$ after the probe trial by cervical dislocation. Hippocampi were dissected on ice, immersed in RNAlater ${ }^{(\mathrm{R})}$, and stored at $-80^{\circ} \mathrm{C}$. RNA was purified using the RNAeasy mini kit (Qiagen) and quality tested by using the Agilent 2100 Bioanalyzer (Agilent Technologies). Total RNA was amplified, reverse-transcribed, and fluorescently labeled with either Cy3-CTP or Cy5-CTP using the Agilent Fluorescent Linear Amplification kit (Agilent Technologies). Two individual samples labeled with $\mathrm{Cy} 3$ or $\mathrm{Cy} 5$ were hybridized $\left(64^{\circ} \mathrm{C}, 20 \mathrm{~h}\right)$ to the mouse Genome $32 \mathrm{~K}$ Oligo Array containing 33,696 transcripts (CapitalBio) by the Biotools Custom Microarray Service (Biotools B\&M Labs). After hybridization, slides were washed, dried and scanned on a LuxScan 10K Microarray Scanner (Capitalio) and analyzed with LuxScan 3.0 Imaging and Analysis software (LuxScan Technologies). Microarray normalization was performed by the Global loess method.

Microarray data were statistically analyzed with the open source R statistical software program v2.9.2 (http://www.r-project.org) using the Linear Model for Microarray Data (Limma) package in Bioconductor (http:// www.bioconductor.org/; Durinck et al., 2009). Statistical gene expression differences between the groups, calculated from measures of log2fold-change ( $M$ values), were analyzed with a linear model and empirical Bayes using the Limma package (Smyth, 2005). The $p$ values correction for multiple testing was performed using Benjamini and Hochberg algorithm (Benjamini and Hochberg, 1995). Statistical gene changes $>1$ or $<-1$ and corrected $p$ values $<0.05$ were considered significant. Mouse microarray data are available at the ArrayExpress database (www.ebi.ac.uk/arrayexpress) under accession number E-MTAB-2067. Gene ontology (GO) analysis of mouse microarray data were performed with ClueGO v1.4 (Bindea et al., 2009) using the following parameters: enrichment/depletion two-sided

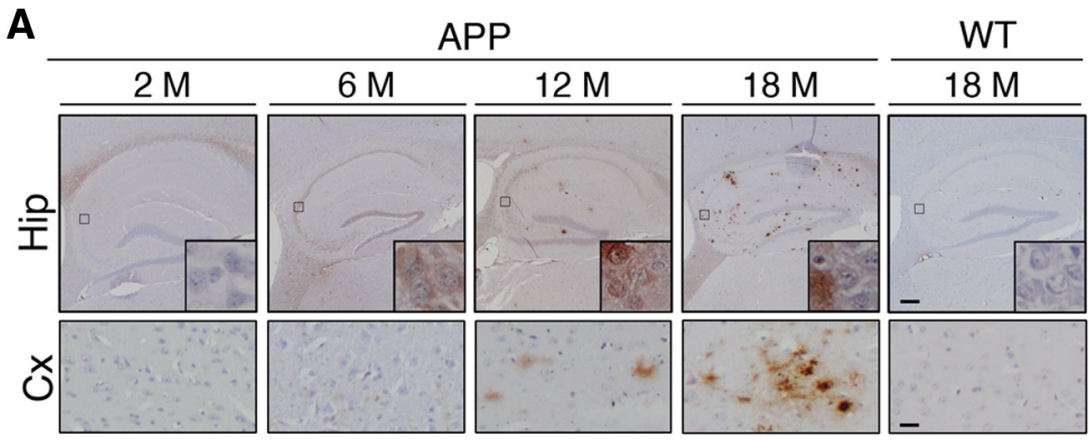

B

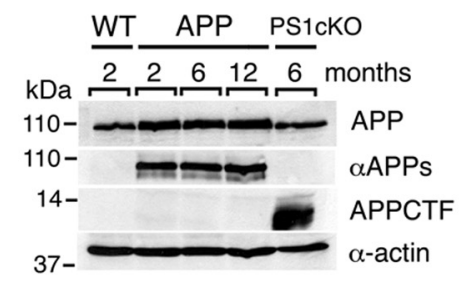

D

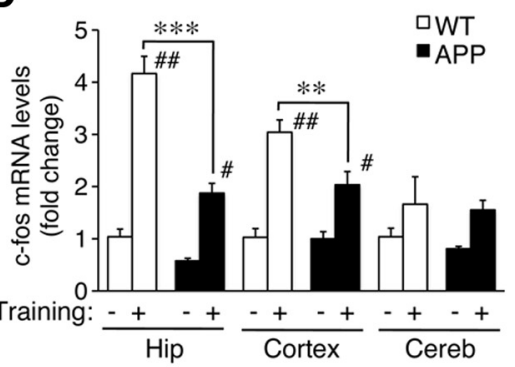

E

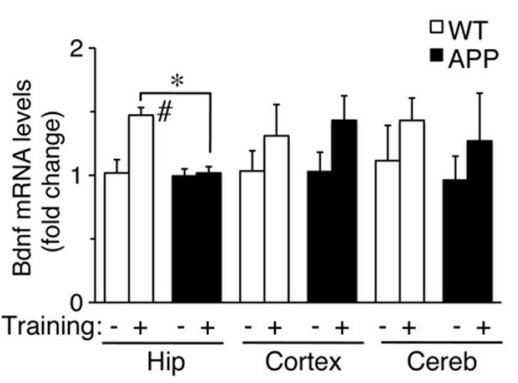

C
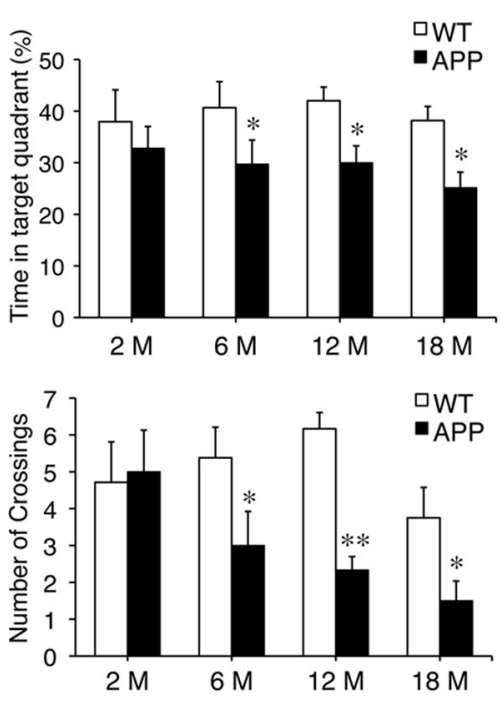

$\mathbf{F}$

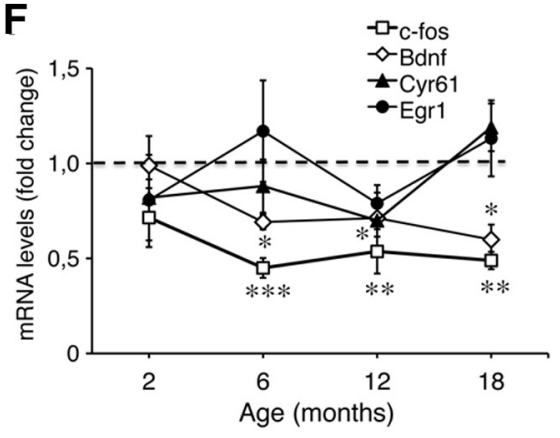

Figure 1. Age-dependent pathological, memory and gene expression changes in $\mathrm{APP}_{\mathrm{Sw}, \text { Ind }}$ mice. $\boldsymbol{A}$, Age-dependent amyloid pathology in the hippocampus of $A P P_{S w, I n d}(A P P)$ mice. Brain sections were stained with an anti-A $\beta 6 E 10$ antibody. M, months; Hip, hippocampus; Cx, cortex. Scale bars: Hp, $250 \mu \mathrm{m} ;$ Cx, $20 \mu \mathrm{m}$. B, Biochemical analysis of APP and APP C-terminal fragment (CTF; "Saeko" antibody) and $\alpha$-secretase-derived $\alpha$ APPs fragment (1736 antibody) in hippocampus of WT, APP Sw,Ind $_{\text {and }}$ presenilin-1 (PS1) conditional knock-out mouse (PS1CK0). C, Age-dependent spatial memory deficits in APP ${ }_{S w, \text { Ind }}$ mice analyzed as number of target platform crossings and percentage time in the target quadrant in the probe test in the MWM. Data are mean \pm SEM ( $n=7-8$ mice/group); ${ }^{*} p<0.05,{ }^{* *} p<0.001 . \boldsymbol{D}, \boldsymbol{E}$, Mice were trained for $5 \mathrm{~d}$ in the water maze $(+)$ or treated identically without training (-) before analysis of $c-f o s$ and $B d n f I V$ mRNAs by qRT-PCR in different brain regions. Levels of mRNA were normalized to Gapdh. Values represent mean \pm SEM ( $n=4-5$ mice/group); ${ }^{*} p<0.01,{ }^{* *} p<0.001,{ }^{* * *} p<0.0001$ compared with controls. $\# p<0.01$, \#\#p $<0.001$ compared with nontrained. $\boldsymbol{F}$, Expression of activity-dependent genes in trained $A_{P P} P_{S W, I n d}$ hippocampus at 2-18 months. Values represent gene changes relative to trained nontransgenic controls. Data represent mean \pm SEM ( $n=4-6$ mice/group); ${ }^{*} p<0.05,{ }^{* *} p<0.001,{ }^{* * *} p<0.0001$ compared with trained controls. Statistical analyses were determined by two-way ANOVA followed by Scheffé's $S$ post hoc test.

hypergeometric statistical test; correction method: Bonferroni; GO term range levels: 3-8; minimal number of genes for term selection: 5; minimal percentage of genes for term selection: $10 \% ; \kappa$-score threshold: 0.5 ; general term selection method: smallest $p$ value; group method: $\kappa$; minimal number of subgroups included in a group: 3 ; minimal percentage of shared genes between subgroups: $50 \%$. 
The CREB-regulated transcriptome consisted of 287 genes, which contained CRE sequences and at least a TATA box in their promoter randomly selected from the CREB Target gene database (http://natural.salk. edu/CREB), and 63 confirmed CREB target genes (Zhang et al., 2005). The CREB gene list was filtered in the whole microarray data according to the above statistical criteria. Heat maps were computed with Mayday software 2.10 (Battke et al., 2010). Differentially expressed CREB genes were submitted to an ontology term enrichment analysis using DAVID (Huang da et al. 2009). Filters used in the functional annotation clusters were established as follows: Similarity Term Overlap 3, Similarity Threshold 0.50, Initial Group size 5, final Group Membership 5, and Multiple Linkage Threshold 0.70.

Quantitative real-time RT-PCR. Human hippocampal RNA was isolated using a combination of Trizol method (Life Technologies) and the RNeasy Mini Kit (Qiagen) according to the manufacturer's instructions. Purified mouse RNA ( $1 \mu \mathrm{g}$; RIN > 8.0) and human RNA $(2 \mu \mathrm{g}$; RIN > 6.0) were reverse-transcribed and amplified using Power SYBR Green PCR Master Mix (15 $\mu$ l; Invitrogen) in an Applied Biosystems 7500 Fast system. Data analysis was performed by the comparative $\Delta \mathrm{Ct}$ method using the $\mathrm{Ct}$ values and the average value of PCR efficiencies obtained from LinRegPCR software. Gene expression in mouse samples was normalized to Gapdh or the geometric mean of three of the most stable following genes determined in each experiment: Gapdh, hypoxanthine guanine phosphoribosyl transferase (Hprt), peptidylprolyl isomerase A (Ppia), and $\beta$-actin or TATA box binding protein (Tbp; Vandesompele et al., 2002). Human genes were normalized to the geometric mean of GAPDH, ACTB, and PPIA, which were the three more stable genes found from the Human Reference Gene Panel (TATAA Biocenter AB).

Statistical analysis. Statistical analysis was performed using one-way ANOVA and Bonferroni or Student-Newman-Keuls post hoc tests. The behavioral data were analyzed using two-way ANOVA with repeated measures and Scheffe's $S$ for post hoc comparisons by using the SuperANOVA program v1.11. Data represent the mean \pm SEM. Differences with $p<0.05$ were considered significant.

\section{Results}

\section{Altered activity-dependent genes are associated with early} memory loss in an AD mouse model

To elucidate transcriptional mechanisms underlying early memory loss in $\mathrm{AD}$, we first analyzed pathological and cognitive changes in a $\beta$-amyloid precursor protein $\left(\mathrm{APP}_{\mathrm{Sw}, \text { Ind }}\right)$ transgenic mouse that develops AD-like pathological changes (Mucke et al., 2000; España et al., 2010a). APP ${ }_{S w, I n d}$ transgenic mice show absence of cerebral $\mathrm{A} \beta$ staining at 2 months, intracellular $\mathrm{A} \beta$ accumulation in the hippocampus at 6 months and amyloid plaques in hippocampus and cortex at 12-18 months (Fig. 1A). Levels of human APP were similarly increased $(\approx 2$-fold $)$ in $\mathrm{APP}_{\text {Sw, Ind }}$ at 2 months $(1 \pm 0.15$-fold $), 6$ months $(0.96 \pm 0.1$-fold $)$, and 12 months $(1 \pm 0.1$-fold; Fig. $1 B)$. To examine $\alpha$-, $\beta$-, and $\gamma$-secretase-mediated APP processing we performed biochemical analyses of $\alpha / \beta$-secretase-derived soluble(s) $\alpha$ APPs and APP C-terminal fragments (CTFs). Levels of $\alpha$ APPs were similar, whereas APP CTFs were absent, in the hippocampus of $\mathrm{APP}_{\mathrm{Sw}_{\text {,Ind }}}$ mice at $2-12$ months of age (Fig. $1 B$ ), indicating increased $A \beta$ but unchanged $\alpha-, \beta$-, and $\gamma$-secretase-mediated APP processing in $\mathrm{APP}_{\mathrm{Sw}, \text { Ind }}$ mice during aging. We next used the MWM test to evaluate hippocampal-dependent spatial memory, a type of memory altered in $\mathrm{AD}$ patients at early disease stages (deIpolyi et al., 2007; Laczó et al., 2011). Two-month-old APP ${ }_{\text {Sw,Ind }}$ and control mice showed similar escape latencies during training, as revealed by a statistically significant day effect (two-way ANOVA: $\left.F_{(4,60)}=15.01 ; p<0.0001\right)$ but no genotype effect $\left(F_{(1,60)}=0.31\right.$, $p>0.05)$, and a significant preference for the target quadrant in the probe trial (quadrant effect, $F_{(3,48)}=9.1, p<0.0001$ ) without significant effect of genotype $\left(F_{(1,48)}=3.45, p>0.05\right.$; Fig. $1 C$; data not shown). By contrast, $\mathrm{APP}_{\mathrm{Sw} \text {,Ind }}$ mice starting at 6 months spent significantly longer latencies during training (two-way
ANOVA, genotype effect, 6 months: $F_{(1,70)}=21.2, p<0.0001 ; 12$ months: $F_{(1,50)}=59.6, p<0.0001$, and 18 months: $F_{(1,70)}=41.5$, $p<0.0001$; Fig. $1 C$; data not shown). $\mathrm{APP}_{\mathrm{Sw} \text {,Ind }}$ mice developed age-dependent long-term spatial memory deficits starting at 6 months as confirmed by significant reduced target quadrant permanencies (genotype effect, $F_{(1,50)}=13.3 ; p<0.001$; age effect: $F_{(3,50)}=0.46 ; p=0.71$ ) and number of target crossings (genotype effect, $F_{(1,50)}=13.5 ; p<0.001$; age effect: $F_{(3,50)}=3.14 ; p<0.03$ ) in the probe test (Fig. $1 C$ ). Groups did not differ in latencies to find the visible platform or swimming speeds ruling out the possibility of visual/motor disturbances in transgenic mice.

To evaluate whether our spatial training protocol was efficient to induce expression of memory-dependent genes, we analyzed by quantitative real-time RT-PCR (qRT-PCR) the levels of activity-dependent CREB target genes, such as $c$-fos and $B d n f$, in basal and trained conditions as previously reported (Guzowski et al., 2001). Spatial training for 3 or $5 \mathrm{~d}$, but not swimming without spatial cues, induced expression of $c$-fos and $B d n f($ exon $I V)$ transcripts in the hippocampus and/or neocortex but not the cerebellum (Fig. 1D,E; data not shown). Interestingly, $c$-fos and $B d n f$ levels were significantly reduced in $\mathrm{APP}_{\mathrm{Sw} \text {,Ind }}$ mice after spatial training but not in basal conditions starting at 6 months (Fig. $1 D-F)$. By contrast, levels of CREB target genes Egr-1 and Cyr61 were unchanged in naive and trained $\mathrm{APP}_{\mathrm{Sw}, \text { Ind }}$ mice at 2-18 months (Fig. $1 F$ ). These results suggested altered expression of CREB target genes regulated by spatial training coinciding with early pathological and memory changes in $\mathrm{APP}_{\mathrm{SW}, \text { Ind }}$ mice.

\section{Altered CREB-dependent transcriptome in $\mathrm{APP}_{\mathrm{Sw} \text {,ind }}$ mice}

To identify gene expression changes associated with early memory deficits in $\mathrm{AD}$, we performed genome-wide transcriptome profile analyses by using mouse cDNA microarrays in the hippocampus of 6-month-old nontransgenic (WT) and $\mathrm{APP}_{\mathrm{Sw}, \text { Ind }}$ mice in two distinct experimental situations: nontrained (naive) and spatial trained conditions (Fig. 2A). Using a linear regression model and empirical Bayes analysis (using $-1 \geq \log 2$-fold $\geq 1$ and $p<0.05$ as statistical criteria), we identified 28 genes (17 upregulated and 11 downregulated) of 33,696 transcripts represented on the mouse genome microarray differentially expressed in $\mathrm{APP}_{\mathrm{Sw}, \text { Ind }}$ mice in basal conditions. By contrast, 932 genes (88\% downregulated and 12\% upregulated) were differentially expressed in $\mathrm{APP}_{\mathrm{Sw} \text {,Ind }}$ mice compared with WT mice after spatial training (Fig. 2A). The microarray data are available in the functional genomic database ArrayExpress (www.ebi.ac.uk/arrayexpress; E-MTAB-2067). Gene-annotation enrichment analysis based on ClueGO, a computational tool that integrates GO terms as well as Kyoto encyclopedia of genes and genomes (KEGG)/ BioCarta pathways (Bindea et al., 2009), revealed a number of functional biological pathways associated with these differentially transcribed genes in trained $\mathrm{APP}_{\mathrm{SW}_{\mathrm{w}} \text { Ind }}$ mice. The biological network with the most significant $k$ score $(>0.5)$ contains 164 differentially expressed genes grouped in several functional GO terms. This network is depicted in Figure $2 B$ as functional biological terms represented as nodes of different colors and sizes, which reflect the enrichment significance of the term, as well as the interrelations (indicated by connecting lines according to $k$ score) of functionally related biological groups deregulated in spatial trained $\mathrm{APP}_{\text {Sw,Ind }}$ mice. Interestingly, 70 genes of this network are included in five principal biological groups: learning, regulation of neurological system, long-term depression, long-term potentiation, and oxidative phosphorylation (Fig. 2B; Table 1). Specifically, the "learning" group is a significant term within the network because it contains five interconnected subgroups ( $n=$ number of genes): learning $(n=10)$, memory $(n=5)$, learning or memory $(n=12)$, visual learning $(n=5)$, 
A
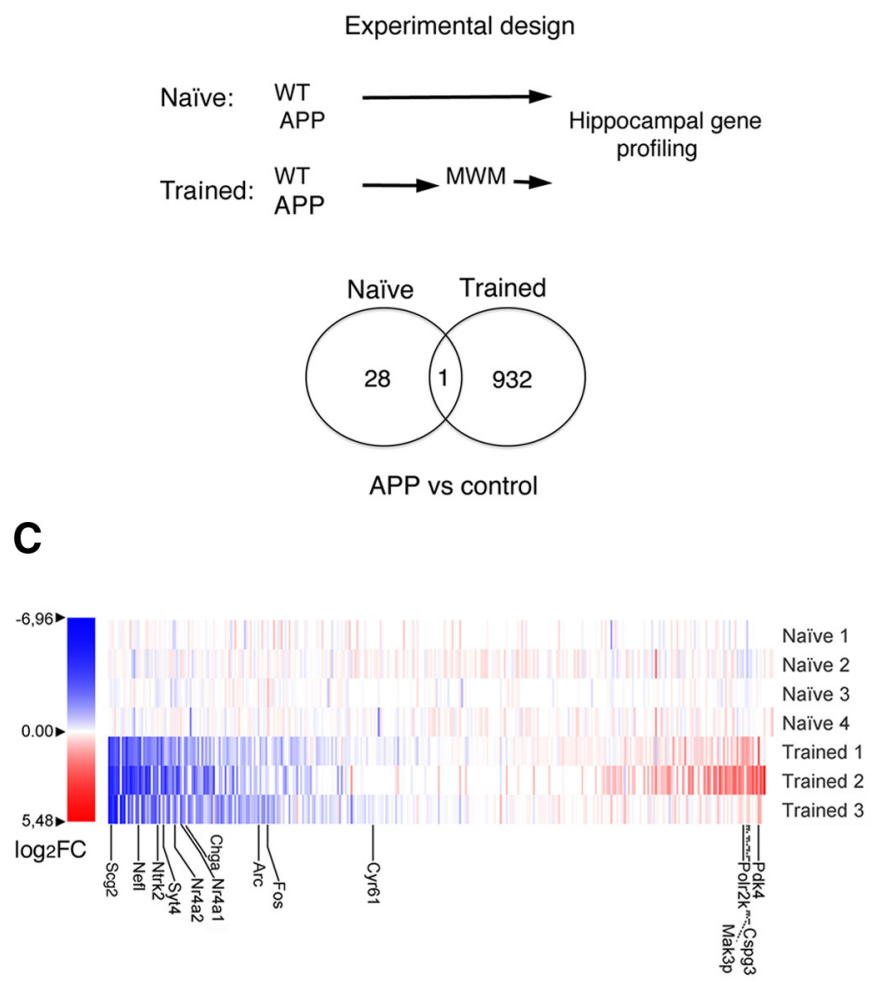

D

6 Months

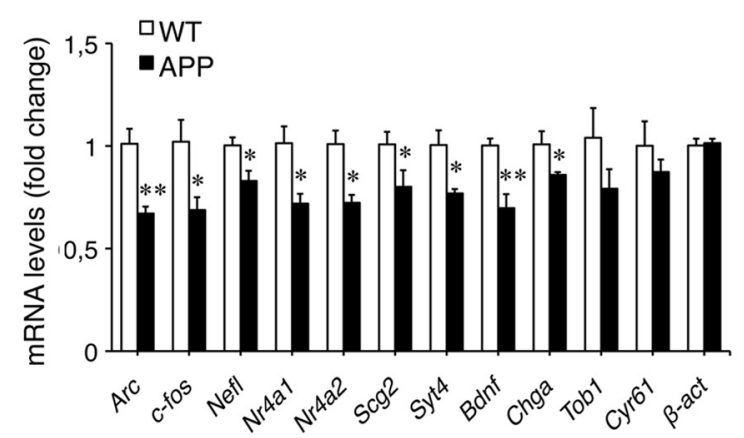

B

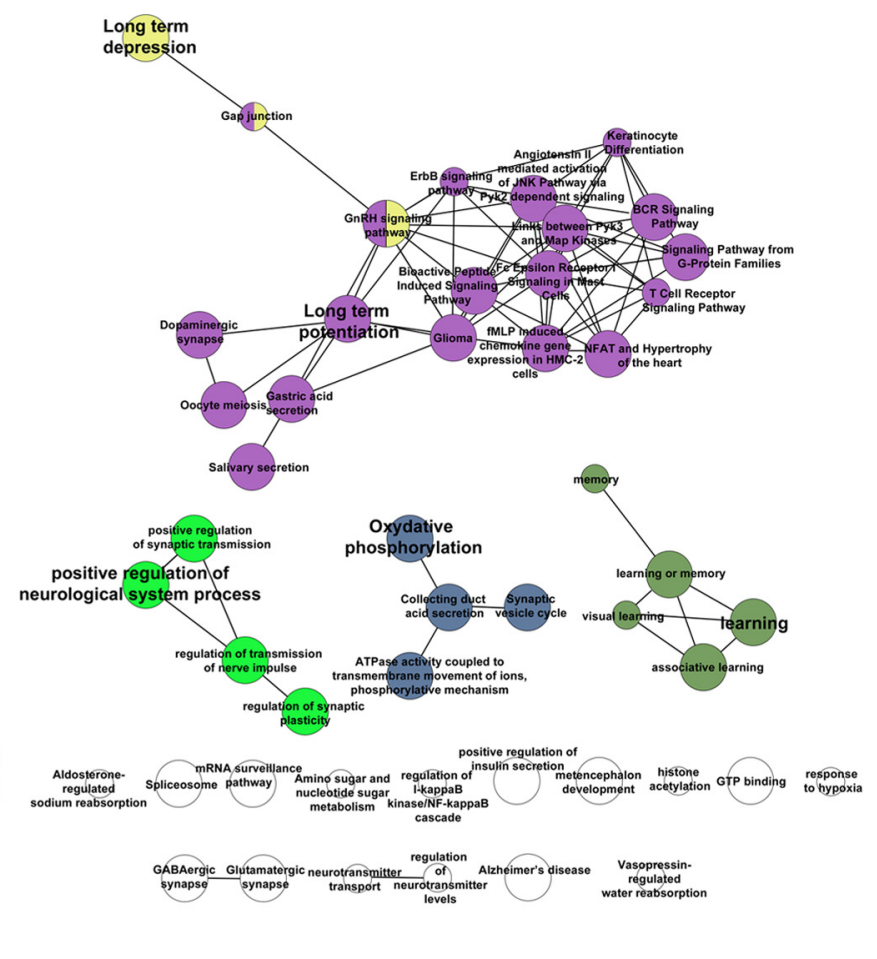

E

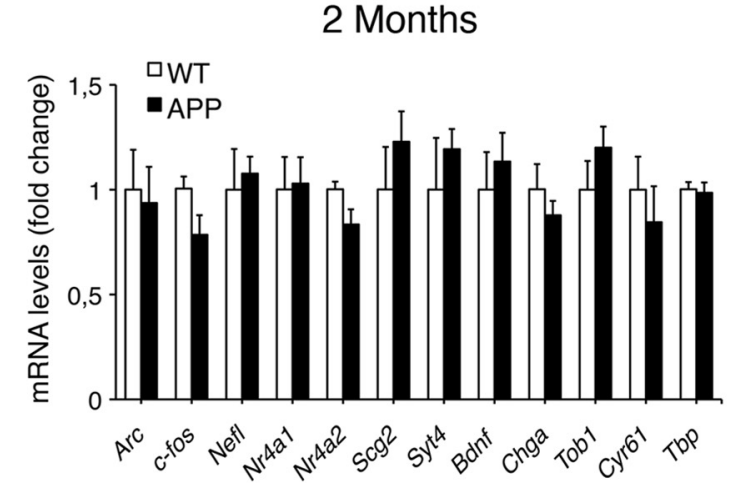

Figure 2. Hippocampal transcriptome changes in spatial trained $\mathrm{APP}_{\mathrm{Sw}_{\mathrm{S}} \text {, nd }}$ mice. $A$, Experimental design of the groups used for gene profiling analyses (top) and Venn diagram (bottom) showing the number of genes differentially expressed in the hippocampus of $\mathrm{APP}_{\mathrm{Sw}, \text { Ind }}$ mice versus control mice in the microarray analysis. $B$, ClueG0 analysis of the whole gene microarray results showing the most significant functional gene network $(k$ score $>0.5)$ altered in the hippocampus of spatial memory trained APP ${ }_{S_{w} \text {,nd }}$ mice compared with trained WT mice. Biological pathways are visualized as colored nodes linked with related groups based on their $\kappa$ score level $(\geq 0.3)$. The node size reflects the enrichment significance of the term and functionally related groups are linked. Not grouped terms are shown in white. C, Heat map of the normalized gene data showing differential expression of CREB target genes in the hippocampus of naive (four top lines) and spatial trained (three bottom lines) $\mathrm{APP}_{\mathrm{Sw}, \text { Ind }}$ mice versus WT mice. Blue and red indicate genes downregulated or upregulated in $\mathrm{APP}_{\mathrm{Sw} \text {, Ind }}$ mice compared with WT mice. (D, E) Expression of genes associated with neurotransmission and synaptic plasticity quantified by qRT-PCR in the hippocampus of spatial trained WT and APP, ${ }_{S w, \text { Ind }}$ mice at 6 months $(\boldsymbol{D})$ and 2 months $(\boldsymbol{E})$. Values represent fold gene changes \pm SEM $\left(n=4-5\right.$ mice/group). Values were normalized to the geometric mean of Ppia, Hprt, and $\beta$-actin. Bdnfrefers to Bdnf IV; ${ }^{*} p<0.05,{ }^{* *} p<0.001(\boldsymbol{D}, \boldsymbol{E})$, compared with WT control or naive. Statistical analyses were determined by one-way ANOVA followed by Bonferroni post hoc test.

and associative learning $(n=7)$. Notably, AD (KEGG:05010) was the functional term with the largest number of differentially expressed genes of the total of the term $(10.53 \% ; n=20$ genes of 190 genes of the term). However, the $\mathrm{AD}$ term was not linked to other groups as it was not sharing enough percentage of genes with any other term.

To identify potential CREB target genes differentially expressed after memory training, we filtered in the raw microarray data 350 genes obtained from the CREB target gene database (http://natural.salk.edu/CREB). Selected genes contained CRE promoter sequences localized within 250 base pairs from the TATA box, a distance that is required for robust transcriptional induction (Conkright et al., 2003a; Zhang et al., 2005). Whereas gene expression profile was similar between naive control and $\mathrm{APP}_{\text {Sw,Ind }}$ mice, 49 CREB target genes ( 45 downregulated and 4 upregulated) were differentially expressed in spatial trained $\mathrm{APP}_{\text {Sw,Ind }}$ mice (Fig. 2C; Table 2). Functional enrichment analysis using DAVID identified several biological groups associated with these genes including metabolism (15\%), cell signaling (14\%), cell adhesion (13\%), neuronal transmission/plasticity/neuritogenesis $(30 \%)$, transcriptional regulation $(10 \%)$, vesicular trafficking (7\%), translation (4\%), cell survival (4\%), and protein degradation (3\%). Expression of genes related to synaptic trans- 
Table 1. Genes and functional groups of the relevant gene network deregulated in the hippocampus of trained APP ${ }_{S w, I n d}$ mice

\begin{tabular}{|c|c|c|c|c|}
\hline Group & GO term & Associated Genes (\%) & Corrected $p$ value & Group/term genes \\
\hline 1 & Learning & 15.38 & 0.0004 & Apbb1, Atp1a2, Chst10, Gabra5, Gria1, Hif1a, Mecp2, Neto1, Neurod2, Ntan1, Ptn, Vdac1 \\
\hline 2 & Regulation of neurological system & 25.00 & 0.0002 & $\begin{array}{l}\text { Camk2a, Hras1, Mecp2, Mgll, Neto1, Neurod2, Ppp3ca, Prkce, Prkcz, Rnf10, Serpine2, } \\
\text { SIc1a3, Snca, Ywhag }\end{array}$ \\
\hline 3 & Long-term depression & 15.28 & 0.00001 & $\begin{array}{l}\text { Adcy9, Calm1, Calm2, Camk2a, Camk2g, Gna11, Gnao1, Gria1, Gucy1b3, Hras1, Itpr1, } \\
\text { Jun, Map3k4, Mapk1,Ppp2ca, Ppp2cb, Prkcb, Prkcc, Tubb3 }\end{array}$ \\
\hline 4 & Oxidative phosphorylation & 10.74 & 0.00001 & $\begin{array}{l}\text { 1110020P15Rik, Atp1a1, Atp1a2, Atp50, Atp6v0a1, Atp6v0d1, Atp6v0e2, Atp6v1c1, } \\
\text { Atp6v1d, Atp6v1g2, Cox15, Cox4i1, Cox7a21, Cox7c, Cplx1, Ndufb2, Ndufb8, Ndufc2, } \\
\text { Sdhb, Syt1, Vamp2 }\end{array}$ \\
\hline 5 & Long-term potentiation & 18.84 & 0.001 & $\begin{array}{l}\text { Abl1, Adcy9, Atp1a1, Atp1a2, Calm1, Calm2, Camk2a, Camk2g, Crk, Gna11, Gnao1, } \\
\text { Gng10, Gria1, Gucy1b3, Hras1, Itpr1, Jun, Map3k4, Mapk1,Ppp1ca, Ppp2ca, Ppp2cb, } \\
\text { Ppp2r2c, Ppp2r5a, Ppp3ca, Ppp3cb, Prkcb, Prkcc, Rpl3, Skp1a, Slc12a2, Tubb3, } \\
\text { Vamp2, Ywhag }\end{array}$ \\
\hline
\end{tabular}

\begin{tabular}{|c|c|c|c|c|}
\hline \multicolumn{5}{|c|}{ Significant nongrouped terms } \\
\hline None & Alzheimer's disease & 10.53 & 0.0002 & $\begin{array}{l}\text { 1110020P15Rik, Apbb1, Apoe, Atp50, Calm1, Calm2, Capn2, Cox4i1, Cox7a2l, Cox7c, } \\
\text { Itpr1, Lpl, Mapk1, Ndufb2, Ndufb8, Ndufc2,Ppp3ca,Ppp3cb, Sdhb, Snca }\end{array}$ \\
\hline None & Spliceosome & 11.43 & 0.0007 & $\begin{array}{l}\text { Cwc15, Dhx15, Hnrnpk, Hspa8, Lsm4, Lsm5, Ncbp2, Nhp211, Prpf19, Sf3a3, Sf3b5, Sfrs7, } \\
\text { Snrpb, Snrpb2, Snrpd3, Syf2 }\end{array}$ \\
\hline None & Glutamatergic synapse & 10.85 & 0.004 & $\begin{array}{l}\text { Adcy9, Dlgap1, Glul, Gnao1, Gng10, Gria1, Itpr1, Mapk1, Ppp3ca, Ppp3cb, Prkcb, Prkcc, } \\
\text { Slc1a3, Slc38a1 }\end{array}$ \\
\hline None & Regulation of insulin secretion & 26.32 & 0.0143 & Hif1a, Nnat, Pfkm, Ppp3cb, Prkce \\
\hline None & GTP binding & 14.81 & 0.017 & Arf1, Arf3, Arf5, Arl3, Gnao1, Hras1, Rraga, Rragb \\
\hline None & Metencephalon development & 13.12 & 0.039 & Hspa5, Kat2a, Ldb1, Mecp2, Neurod2, Pfdn1, Sdf4, Serpine2 \\
\hline None & GABAergic synapse & 10.90 & 0.041 & Adcy9, Gabarap, Gabarapl1, Gabra5, Glul, Gnao1, Gng10, Prkcb, Prkcc, Slc38a1 \\
\hline
\end{tabular}

Genes are grouped according to their biological function as determined by $\mathrm{G} 0$ analysis of the mouse microarray data using ClueG0 v1.4. Associated genes indicates the percentage of changed genes of the total of genes of the term.

mission and plasticity was validated by qRT-PCR. Thus, Arc, c-fos, neurofilament (Nefl), nuclear receptor sub 4, 1, and 2 (Nr4a1, Nr4a2), secretogranin II (Scg2), synaptotagmin IV (syt4), chromogranin A (Chga), transducer of ErB-2 (Tob1; $p=0.18)$, Rab2a (10\% decrease), and Ptp4a1 (14\% decrease) were downregulated in the hippocampus of trained $\mathrm{APP}_{\mathrm{Sw}, \text { Ind }}$ mice at 6 months $(p<$ 0.05 ) but not at 2 months (Fig. $2 D, E$ ). These results suggested deregulation of a specific CREB-dependent gene program associated with early memory loss in trained $\mathrm{APP}_{\mathrm{Sw}, \text { Ind }}$ mice.

\section{Activity-dependent Crtcl transcription is deregulated in $\mathrm{APP}_{\text {Sw,ind }}$ mice}

We next investigated the molecular mechanisms underlying differential deregulation of CREB target genes in $\mathrm{APP}_{\mathrm{Sw}_{\text {, Ind }}}$ mice. Biochemical analysis revealed similar levels of phosphorylated (pSer133) and total CREB (WT: $1.0 \pm 0.1$ vs $\mathrm{APP}_{\mathrm{Sw}_{\text {,Ind }}}: 1.2 \pm$ 0.1 -fold change) in the hippocampus of 6-month-old naive control and $\mathrm{APP}_{\mathrm{Sw} \text {,Ind }}$ mice $(p>0.05$; Fig. $3 A)$. Spatial training similarly enhanced CREB phosphorylation in control $(1.8 \pm 0.2-$ fold) and $\mathrm{APP}_{\mathrm{Sw} \text {,Ind }}(2.2 \pm 0.4$-fold) mice (one-way ANOVA, $p>$ 0.05). Total levels of Crtcl were similar in naive or trained WT and $\mathrm{APP}_{\mathrm{Sw}, \text { Ind }}$ mice (naive mice, WT: $1.0 \pm 0.1$ vs $\mathrm{APP}_{\mathrm{Sw}, \text { Ind }}$ : $1.0 \pm 0.07$-fold change). By contrast, phosphorylated Crtc1 at Ser151, a site that regulates Crtc1 nuclear translocation and transcription (Altarejos et al., 2008; España et al., 2010b), was significantly increased in naive $\mathrm{APP}_{\mathrm{Sw}, \text { Ind }}$ mice $(p<0.02)$. Interestingly, spatial training significantly decreased Crtc1 phosphorylation in both genotypes, although levels of phosphorylated Crtc1 were significantly higher in $\mathrm{APP}_{\mathrm{Sw}, \text { Ind }}$ mice $(p<0.04$; Fig. $3 A$ ). Reduced levels of Crtc1, but not CREB, phosphorylated CREB or CBP, were found in nuclear fractions of $\mathrm{APP}_{\mathrm{Sw} \text {,Ind }}$ forebrains (Fig. 3B). Confocal microscopy analysis revealed a clear increased of $\mathrm{Crtc1}$ in the nucleus of CA3 pyramidal neurons of WT mice after spatial training (nucleus/cytoplasm ratio, trained: 1.25 vs naive: 1.0 ), whereas nuclear $\mathrm{Crtc1}$ was reduced in trained $\mathrm{APP}_{\mathrm{Sw} \text {,Ind }}$ mice $(\sim 1.05$; Fig. $3 C)$. By contrast, Crtc1 nuclear trans- location was more diffuse and sparser in dentate gyrus (DG) granular neurons and occurs only in specific CA1 pyramidal neurons in $\mathrm{WT}$ but not $\mathrm{APP}_{\mathrm{Sw} \text {,Ind }}$ mice after spatial training (Fig. $3 C$ ).

These results raised the possibility that Crtcl dysfunction could cause transcriptional changes in $\mathrm{APP}_{\mathrm{Sw} \text {,Ind }}$ mice. To analyze this possibility, we examined whether the above CREB target genes were dependent on Crtc1. In 10 DIV primary neurons, synaptic activity significantly enhanced ( $\sim 5$ - to 100 -fold) the expression of Arc, c-fos, Nefl, Nr4a1, Nr4a2, Scg2, Syt, and Bdnf, whereas only slightly increased Chga, Tob1, and Cyr61 levels (1.5fold; Fig. 3D). A Crtc1 shRNA (España et al., 2010b), which efficiently decreases $C r t c 1$ transcripts (scramble: $100 \pm 10 \%$ vs Crtc1 shRNA: $23.3 \pm 1.7 \%, p<0.0001$ by one-way ANOVA) and CREB transcriptional activity (scramble shRNA: $12.5 \pm 0.9$ vs Crtc1 shRNA: $5.8 \pm 0.8$-fold, $p<0.0001$ by one-way ANOVA), significantly reduced expression of those genes, whereas barely affected Tob1 and Cyr61 (Fig. 3D). Interestingly, Crtc1 transcripts were decreased by synaptic activity, suggesting that sustained neuronal activity downregulates Crtcl expression. Western blotting analysis confirmed increased Nr4a1 (NUR77), Nr4a2 (NURR1), c-Fos, and BDNF proteins in response to neuronal activity and their Crtcl dependency (Fig. 3E). ChiP analyses using antibodies against Crtc1 and CREB (positive control) and an irrelevant IgG (negative control) demonstrated that Crtc1 is specifically recruited to the promoter regions of $c$-fos, Nr4al, and Nefl but not Cyr61 in an activity-dependent manner, which contrasts with binding of CREB to $c$-fos, $N r 4 a 1$, and Cyr61 promoters independently of stimulus (Fig. $3 F$ ). Finally, CA3 pyramidal neurons expressing high Crtcl levels show elevated Arc expression compared with neurons with low or very low Crtc1 (Fig. 3G).

\section{Crtcl overexpression rescues amyloid-induced transcriptional and cognitive deficits}

The above results suggested that disruption of Crtcl could mediate early $\mathrm{A} \beta$-induced transcriptional and memory deficits. As a proof of concept, we expressed Crtc1-myc in vivo by using AAV 
Table 2. Potential CREB target genes differentially expressed in the hippocampus of trained APP ${ }_{S w, I n d}$

\begin{tabular}{|c|c|c|c|c|c|}
\hline Biological pathway/gene & Gene & GenBank & Log fold-change & $p$ & Biological function \\
\hline \multicolumn{6}{|l|}{ Metabolism } \\
\hline Lactate dehydrogenase A & Ldha & NM_010699 & -5.08 & 0.0001 & Conversion of L-lactate to pyruvate \\
\hline ATP synthase subunit $c 1$ & $\operatorname{Atp} 5 g 1$ & NM_007506 & -4.00 & 0.001 & ATP synthesis \\
\hline Enolase $2 / \gamma$-enolase & Eno2 & NM_013509 & -3.03 & 0.028 & Glycolysis \\
\hline $\mathrm{Na}^{+} / \mathrm{K}+$ ATPase $\alpha 1$ & Atp1a1 & NM_144900 & -2.37 & 0.01 & $\mathrm{Na}^{+} / \mathrm{K}^{+}$transport, ATP synthesis \\
\hline Isopentenyl-diphosphate $\delta$-isomer1 & Idi1 & NM_145360 & -1.86 & 0.008 & Isoprenoid biosynthetic pathway \\
\hline Pyruvate dehydrogenase kinase 4 & Pdk4 & NM_013743 & 1.78 & 0.019 & Pyruvate metabolism \\
\hline $\mathrm{N}(\alpha)$-acetyltransferase 50 & Naa50 & NM_028108 & 1.12 & 0.025 & Acetyltransferase activity \\
\hline \multicolumn{6}{|l|}{ Neurotransmission, plasticity, ves traff } \\
\hline Neuritin/cpg 15 & Nrn1 & NM_153529 & -4.34 & 0.001 & Neuritogenesis, synaptic plasticity \\
\hline Secretogranin II & $\operatorname{scg} 2$ & NM_009129 & -3.76 & 0.007 & Vesicle release, neuromodulation \\
\hline Glutamate receptor GluA1 & Gria1 & NM_008165 & -3.00 & 0.005 & Neurotransmission, memory \\
\hline Syntaxin 18 & Stx18 & NM_026959 & -1.40 & 0.042 & SNAP receptor \\
\hline Leucin rich repeat TM Neuronal 1 & Lrtm1 & NM_028880 & -1.36 & 0.049 & Synapse formation, axon traficking \\
\hline \multicolumn{6}{|l|}{ Cell adhesion/cytoskeleton } \\
\hline Claudin 5 & Cldn5 & NM_013805 & -2.92 & 0.02 & Component of tigh junctions \\
\hline Neurofilament, light peptide & Nefl & NM_010910 & -2.60 & 0.0001 & Neurofilament member \\
\hline Fibronectin 1 & Fn1 & NM_010233 & -2.38 & 0.042 & Cell adhesion and migration \\
\hline Brain angiogenesis inh 1-ass.prot 2 & Baiap2 & NM_130862 & -2.25 & 0.01 & Actin cytoskeleton, neuritogenesis \\
\hline Angio-associated migratory protein & Aamp & NM_146110 & -1.69 & 0.003 & Cell migration \\
\hline Chondroitin sulfate proteoglycan 5 & Cspg5 & NM_013884 & -1.64 & 0.013 & Dendritic branching and synapses \\
\hline Calsyntenin 3 & Clstn3 & NM_153508 & -1.46 & 0.005 & Cell adhesion, associative learning \\
\hline Myelin oligodendrocyte glycoprotein & Mog & NM_010814 & -1.18 & 0.002 & Maintenance myelin sheath \\
\hline Neurocan & Ncan & NM_007789 & 1.14 & 0.03 & Neuronal adhesion, neurite growth \\
\hline Cyclin-dependent kinase 16 & $C d k 16$ & NM_011049 & -1.09 & 0.03 & Neurite outgrowth, neuron migration \\
\hline \multicolumn{6}{|l|}{ Transcriptional regulation } \\
\hline Histone cluster $1, \mathrm{H} 2 \mathrm{bj}$ & Hist1h2bj & NM_178198 & -3.58 & 0.001 & Compaction of chromatin \\
\hline Activating Transcriptional factor 4 & Atf4 & NM_009716 & -3.29 & 0.004 & Transcription activator, binds to CRE \\
\hline Jun oncogene & Jun & NM_010591 & -2.64 & 0.002 & Transcription factor \\
\hline Inhibitor of DNA binding 2 & Id2 & NM_010496 & -2.3 & 0.032 & Inhibitor of transcription factors \\
\hline Nuclear receptor sub 4, 2 & Nr4a2 & NM_0113613 & -1.80 & 0.007 & Transcription factor \\
\hline Nuclear receptor sub 4, 1 & Nr4a1 & NM_010444 & -1.74 & 0.028 & Transcription factor \\
\hline Polymerase (RNA) II polypeptide K & Polr2k & NM_023127 & 1.013 & 0.042 & RNA polymerase \\
\hline \multicolumn{6}{|l|}{ Translation/cell survival } \\
\hline Poly(A)binding protein, cytoplas. 1 & Pabpc1 & NM_008774 & -3.75 & 0.003 & Poly(A) translation, initiation \\
\hline Translation initiation factor 3, sub D & Eif3d & NM_018749 & -1.92 & 0.009 & Component of the elF-3 complex \\
\hline Programmed cell death 7 & Pded7 & NM_016688 & -1.43 & 0.025 & Promotes apoptosis \\
\hline \multicolumn{6}{|l|}{ Protein Degradation } \\
\hline Myeloid leukemia factor 2 & Mlf2 & NM_145385 & -3.03 & 0.0001 & Protein degradation tagging activity \\
\hline Ubiquitin-conjugated enzyme E2G 1 & Ube2g1 & NM_025985 & -1.31 & 0.041 & Attachment of ubiquitin to proteins \\
\hline \multicolumn{6}{|l|}{ Unclassified } \\
\hline Abhydrolase domain containing 11 & Abhd11 & NM_145215 & -2.38 & 0.001 & Deleted Williams-Bernes syndrome \\
\hline
\end{tabular}

Relative mRNA levels in the hippocampus of APP $_{S_{\text {W.Ind }}}$ mice compared to nontransgenic control mice after spatial training in the MWM. Relevant genes from microarray hybridizations are listed in each column, with log2-fold changes indicating relative decrease $(<1)$ or increase $(>1)$ of mRNA levels in $\mathrm{APP}_{\mathrm{Sw} \text {, Ind }}$ mice compared with controls. Genes are grouped according to their biological pathway and relative gene expression changes. A gene could be assigned to more than one biological function term. Only genes with $p<0.05$ are given.

vector AAV2/10, a serotype characterized by high and specific gene transduction in neurons of the brain (Klein et al., 2008). AAV-Crctl efficiently expressed functional Crtc1-myc as shown by enhancement of synaptic activity-induced Crtc1-myc nuclear trans- location (data not shown) and CREB-dependent transcription by a CRE-luciferase assay in hippocampal neurons (AAV-GFP: vehicle, $0.10 \pm 0.01$ and $\mathrm{FSK} / \mathrm{KCl}, 9.3 \pm 2.0 ; \mathrm{AAV}$-Crtc1: vehicle, $0.17 \pm 0.04$ and FSK/KCl, $16.8 \pm 4.2$-fold change; one-way 
A
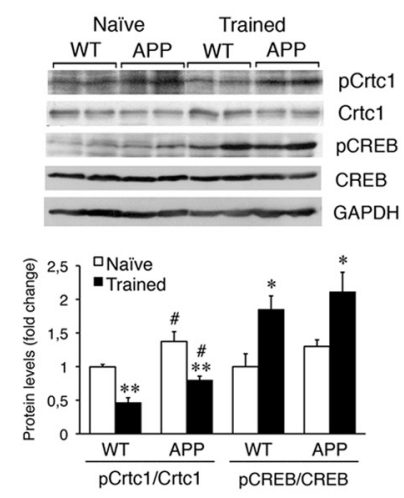

C
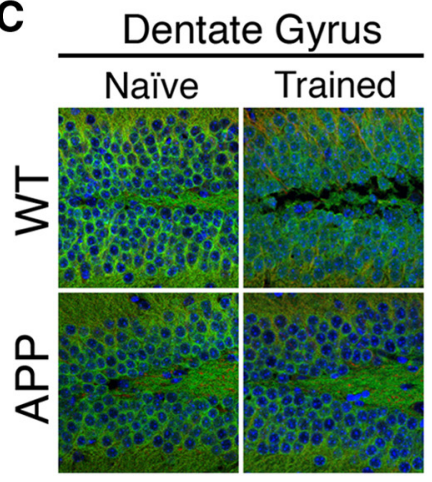

F
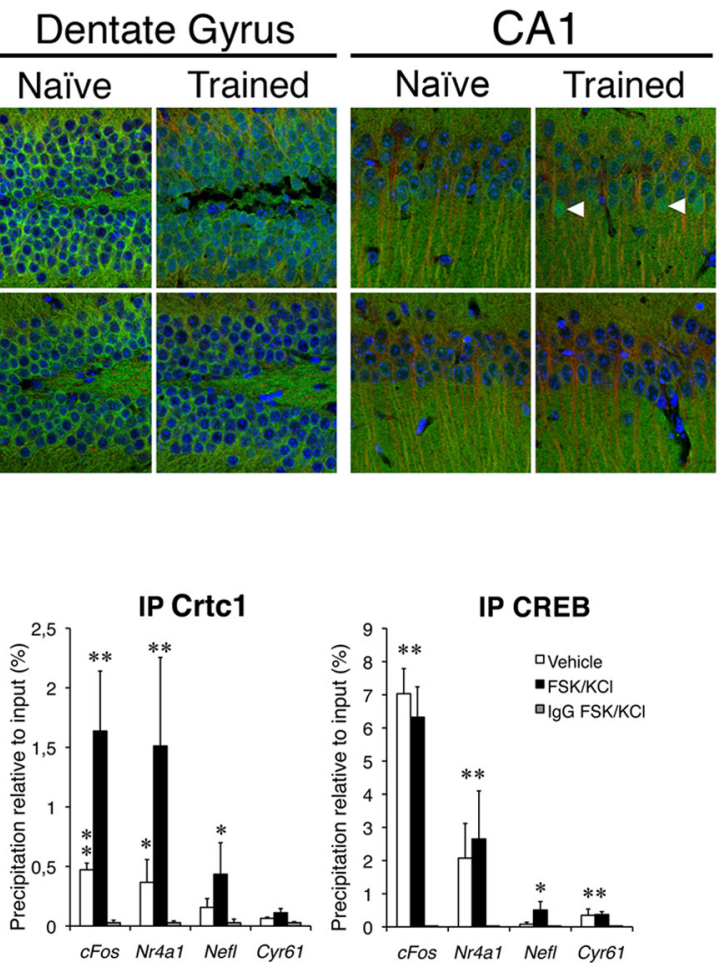

D
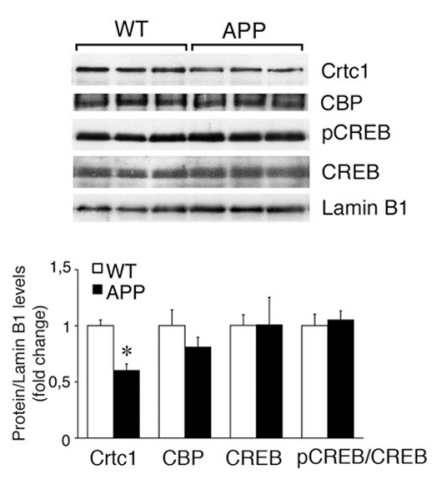
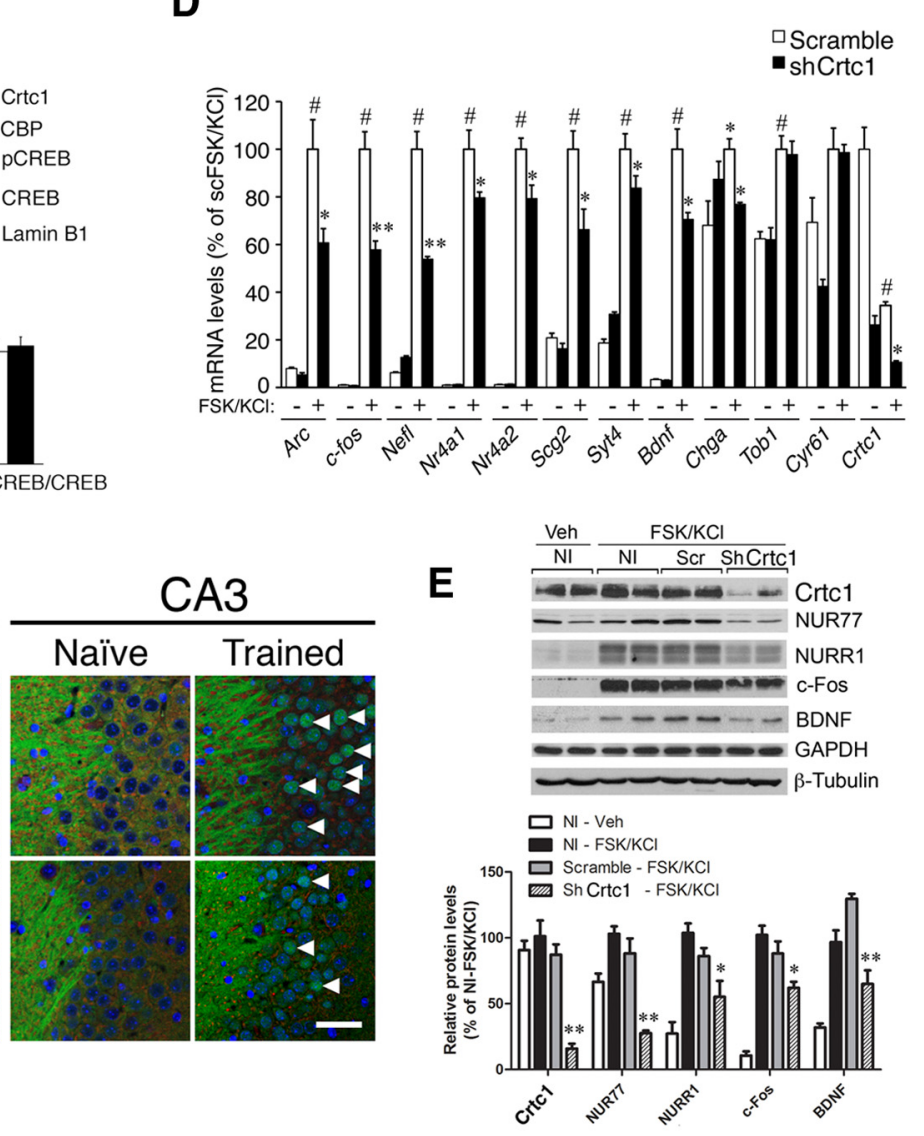

G

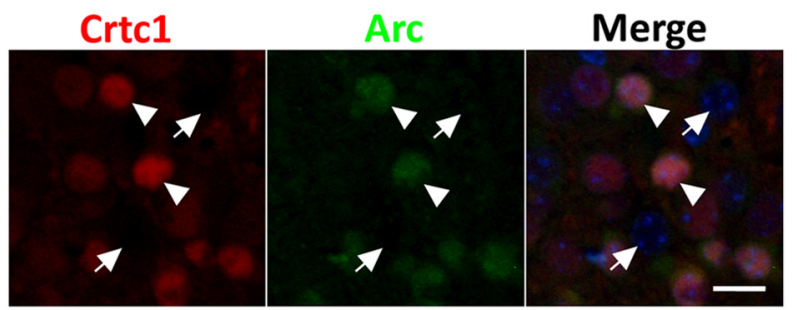

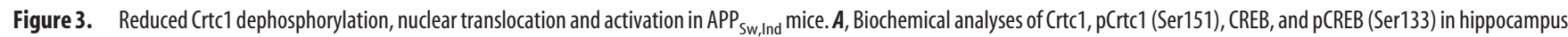
of naive and memory trained control (WT) and APP ${ }_{S w, \text { Ind }}$ mice. Values represent fold changes \pm s.e.m $\left(n=4\right.$ mice/group); ${ }^{*} p<0.05$, ${ }^{* *} p<0.002$, and \#p $<0.05$ compared with naive and WT mice, respectively. $\boldsymbol{B}$, Reduced (rtc1 and unchanged CBP, CREB, and $p$ CREB in purified nuclear brain extracts of trained APP Sw, Ind $_{\text {mice. }}$ Data are the mean \pm SEM $\left(n=3-4\right.$ mice/group); ${ }^{*} p<0.05$ compared with controls. C, Confocal images showing localization of Crtc1 (green) and MAP2 (red) in DG, CA1, and CA3 hippocampus in naive and spatial trained mice. Nuclear translocation of Crtc1, as revealed by colocalization with Hoechst (blue; arrowheads) is more evident in CA3 hippocampal neurons of WT mice after spatial training, and reduced in trained APP ${ }_{\text {Sw, Ind }}$ mice. CA3: Green (rtc1 staining in the left side of the images represents terminal axons from DG granular cells (mossy fibers), whereas dendritic MAP2 staining (red) is detected as punctuate staining due to its transversal position in the coronal sections. Images ( $20 \times$, zoom 0.5$)$ are representative of $n=5-6$ mice/group. Scale bar, $40 \mu \mathrm{m}$. D, Expression of CREB target genes in 10 DIV cultured neurons expressing scramble or Crtc1 shRNAs treated with vehicle $(-)$ or FSK/KCl (+). Data are normalized to Gapdh and represent the mean \pm SEM $(n=3)$; \#p $<0.0001,{ }^{*} p<0.05,{ }^{* *} p<0.01$ compared with vehicle-treated or FSK/KCl-treated control neurons. $E$, Protein levels of Crtc1-dependent genes in noninfected (NI) or scramble (Scr)- or Crtc1 shRNA-infected neurons (10 DIV; $n=4-5$ cultures per group); ${ }^{*} p<0.05,{ }^{* *} p<0.01$ compared with scramble-FSK/KCl. Values are normalized to $\beta$-tubulin. $F$, ChiP analysis shows activity-dependent recruitment of Crtc 1 to specific gene promoters. IgG, Irrelevant antibody. Data represent the mean \pm SEM of three independent experiments; ${ }^{*} p<0.05,{ }^{* *} p<0.005$, compared with IgG FSK/KCI IP. G, Expression of Arc (green) is evident in neurons expressing high Crtc1 levels (red; arrowheads) compared with neurons with very low Crtc1 levels (arrows) in CA3 hippocampus of WT trained mice. Scale bar, $20 \mu \mathrm{m}$. Statistical analysis was determined by one- or two-way ANOVA followed by Student-Newman-Keuls post hoc test.

ANOVA, $p<0.03)$. Viral injections were localized in the septal (dorsal) hippocampus since this region is critical for spatial water-maze acquisition and memory (Moser et al., 1995). AVVCrtcl injection resulted in stable and long-term ( $>1$ month) expression of Crtc1-myc mRNA and protein mainly in neurons of CA1 and CA3 pyramidal layers, stratum oriens, and hilus of the DG (Figs. $4 A-C$, and data not shown). Crtc1-myc overexpression lead to an increase of Crtc1-myc nuclear translocation in AVV-
Crtc1-myc injected mice (data not shown). The performance of all groups improved significantly during spatial training in the water maze (day 1 vs day $5, p<0.001$ ), although the latencies of AAV-GFP-injected $\mathrm{APP}_{\mathrm{Sw}, \text { Ind }}$ mice were significantly higher than the rest of groups (two-way ANOVA, genotype effect: $F_{(3,135)}=$ 10.2; day effect: $F_{(4,135)}=45.6 ; p<0.0001$; Fig. $\left.4 D\right)$. In the probe test, nontransgenic mice injected with AAV-GFP and AAV$\mathrm{Crtc1}$, and $\mathrm{APP}_{\mathrm{Sw}, \text { Ind }}$ mice injected with $\mathrm{AAV}-\mathrm{Crtc1}$ displayed 
A

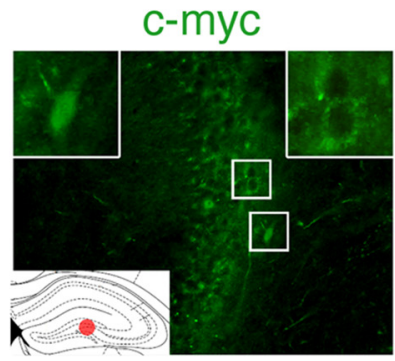

B
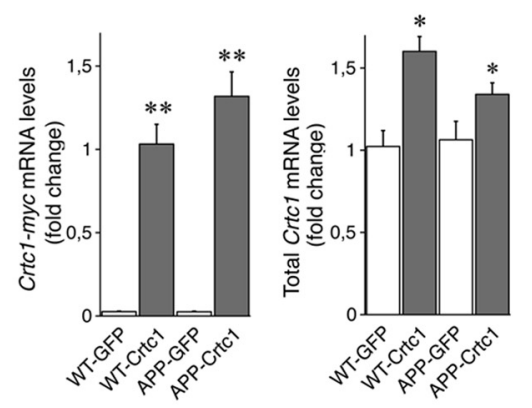

C

$\mathbf{E}$

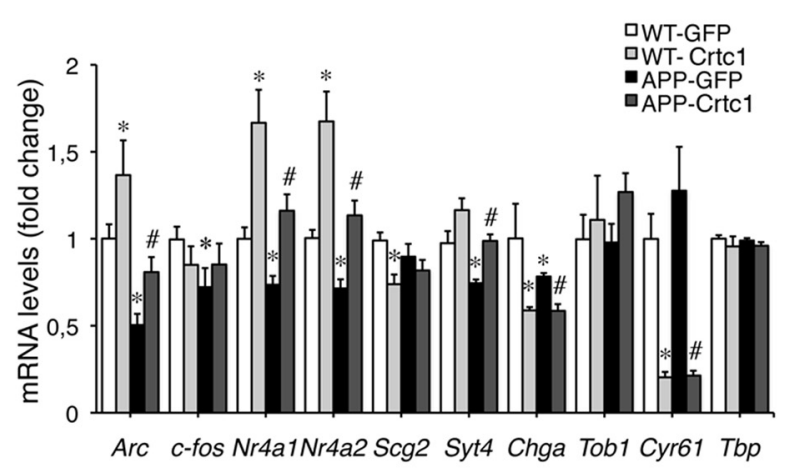

D
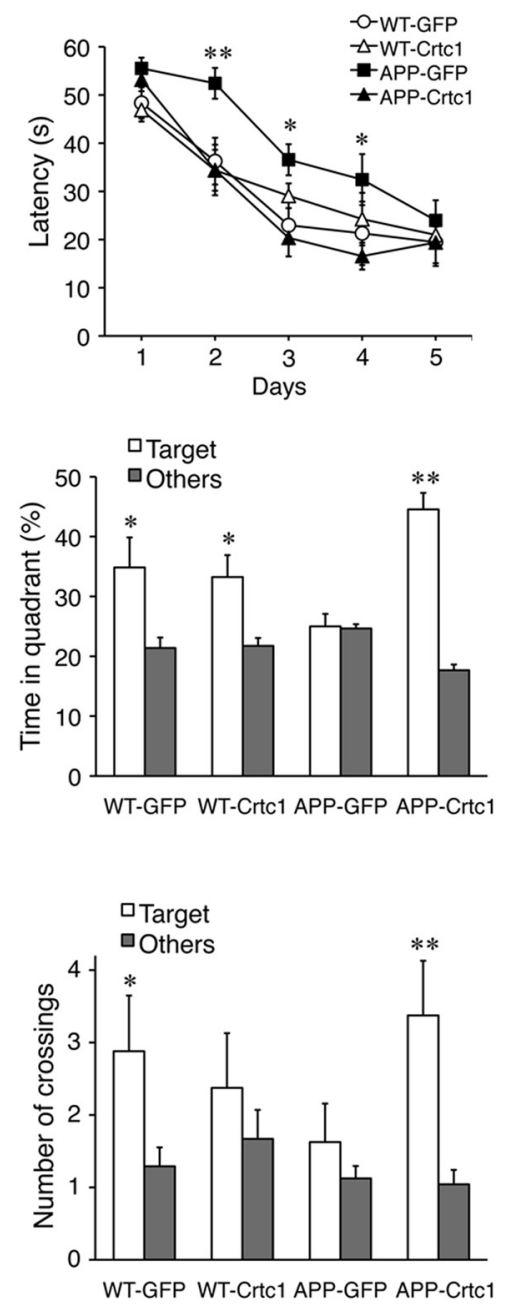

Figure 4. Adeno-associated viral-mediated Crtc1 overexpression prevents early $A \beta$-induced transcriptional and memory deficits. $A$, Long-term Crtc1-myc expression in the mouse dorsal hippocampus. Overexpression of Crtc1-myc (green) in CA3 pyramidal neurons (NeuN, red) three weeks after stereotaxic intrahippocampal AAV-Crtc1-myc injection. Injection point is indicated in red in the brain diagram. Insets, Magnified images of the selected regions (square) showing (rtc1-myc localization in the neuronal nucleus (left inset) or cytoplasm (right inset). Scale bar, $50 \mu \mathrm{m}$. $\boldsymbol{B}$, Increased Crtc1-myc and total Crtc1 mRNAs normalized to Gapdh in AAV-Crtc1-myc-injected mice. Data are the mean \pm SEM $\left(n=4-5\right.$ mice/group); ${ }^{*} p<0.05,{ }^{* *} p<0.001$, compared with AAV-GFP-injected control mice. C, (rtc1-myc protein levels in injected mice. Data are the mean \pm SEM ( $n=4$ mice/group); ${ }^{* *} p<0.001$ compared with AAV-GFP-injected control mice. D,

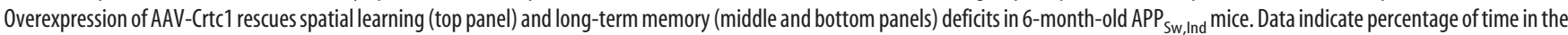
target quadrant or number of target platform crossings compared with the average of time or number of crossings in the three other quadrants, respectively. Data are the mean \pm SEM $(n=8$ mice/group); ${ }^{*} p<0.002,{ }^{* *} p<0.0001$, compared with controls or the average of other quadrants as determined by two-way ANOVA. $E$, Crtc1-dependent gene expression normalized to the geometric mean of Gapdh, Hprt1, and Tbp in hippocampus of AAV-injected mice. Data represents the mean \pm SEM $\left(n=4-5\right.$ mice/group); ${ }^{*} p<0.05$ compared with WT-GFP; \#p $<0.05$ compared with APP-GFP mice. Statistical analyses were determined by one- or two-way ANOVA followed by Student-Newman-Keuls post hoc test.

significantly higher occupancies and number of crossings in the target quadrant/platform relative to other quadrants $(p<0.001)$, whereas $\mathrm{APP}_{\mathrm{Sw} \text {,Ind }}$ mice injected with $\mathrm{AAV}$-GFP failed to show such a preference ( $p=0.9$; two-way ANOVA, Scheffé's S post hoc test; Fig. $4 D$ ). Notably, Crtcl gene delivery significantly increased $A r c, N r 4 a 1, N r 4 a 2$, and Syt4 levels in control and $\mathrm{APP}_{\mathrm{Sw}_{\mathrm{w} \text { Ind }}}$ mice, which were significantly different from those of AAV-GFP-injected $\mathrm{APP}_{\mathrm{Sw}, \text { Ind }}$ mice, but decreased Chga, Scg2 and Cyr61 or unaffected $c$-fos, Tob1, and Tbp (Fig. 4E). These results demonstrated that Crtc1 efficiently ameliorates hippocampal-dependent learning and memory deficits in $\mathrm{APP}_{\mathrm{S} \text {, Ind }}$ mice by enhancing the expression of a specific subset of Crtcl target genes.
CRTC1-dependent transcriptional changes at early AD stages To investigate changes in CRTC1-dependent genes during the progression of $\mathrm{AD}$ pathology, we analyzed gene expression in the hippocampus of 68 individuals pathologically classified as controls (no pathology, $n=16$ ), early (Braak I-II, $n=22$ ), intermediate (Braak III-IV, $n=14$ ), and advanced (Braak V-VI, $n=16$ ) $\mathrm{AD}$ pathological cases (Braak et al., 2006). Brain samples were closely matched for age, neurofibrillary pathology, postmortem delay and RIN values (Table 3). To faithfully compare gene expression across different pathological stages, transcripts were normalized to the geometric mean of multiple reference genes (Vandesompele et al., 2002). We observed a differential pattern of 
Table 3. Summary of human brain samples used in the gene expression assays

\begin{tabular}{llllll}
\hline Braak stage & $n$ & Sex & Age & PMD (h) & RIN \\
\hline Control & 16 & $6 \mathrm{~F} / 10 \mathrm{M}$ & $49.9 \pm 7.8$ & $7.1 \pm 3.6$ & $6.22 \pm 1.2$ \\
I-II & 22 & $4 \mathrm{~F} / 18 \mathrm{M}$ & $69.6 \pm 10.2$ & $6.0 \pm 3.6$ & $6.26 \pm 0.9$ \\
III-IV & 14 & $8 \mathrm{~F} / 6 \mathrm{M}$ & $78.6 \pm 6.3$ & $5.0 \pm 3.9$ & $6.49 \pm 1.0$ \\
V-VI & 16 & $8 \mathrm{~F} / 8 \mathrm{M}$ & $79.8 \pm 7.2$ & $7.4 \pm 5.0$ & $6.27 \pm 0.9$
\end{tabular}

Data are represented as mean \pm SD. F, Female; M, male; PMD, postmortem delay; h, hours; RIN, RNA integrity number.

$\operatorname{Arc}$ mRNA expression across $\mathrm{AD}$ stages $\left(F_{(3,64)}=4.7, p<0.005\right)$ with significant reduced levels at early (Braak I-II) and intermediate (Braak III-IV) pathological stages compared with controls (one-way ANOVA, $p<0.02$; Fig. 5A). Similarly, Nr4a2 levels were downregulated at Braak III-IV and V-VI stages compared with controls ( $p<0.04$; Fig. 5A). By contrast, Cyr61 and CRTC1 transcripts were not significantly changed during AD pathological progression (Fig. 5A). Biochemical analysis revealed a reduction of both total and phosphorylated CRTC1 in human hippocampus at Braak IV and V-VI pathological stages (Fig. 5B). These results indicated dysregulation of CRTC1-dependent transcription associated with decreased CRTC1 levels in human brain at intermediate Braak III-VI pathological stages.

\section{Discussion}

Gene expression changes in the brain occur at early AD stages (Blalock et al., 2004; Bossers et al., 2010; Twine et al., 2011), but whether deregulation of brain transcriptome causes memory deficits in this disease is still unclear. Genome-wide transcriptome analyses revealed significant differences in genes related to neurotransmission, synaptic plasticity, learning/memory, and oxidative phosphorylation in the hippocampus of memory trained $\mathrm{APP}_{\mathrm{Sw}, \text { Ind }}$ mice, whereas $\mathrm{AD}$ was the pathway with the highest number of changed genes relative to those of the term. Specifically, a Crtcl-dependent gene program related to synaptic function and plasticity was deregulated at early $\mathrm{AD}$-related pathological and cognitive stages. Agedependent Crtcl transcriptional changes occurred in brain regions affected by amyloid pathology and essential for memory encoding (i.e., hippocampus), a result consistent with previous reports showing region-, neuropathology-, and age-dependent gene changes in AD (Liang et al., 2010; Twine et al., 2011). Notably, synaptic genes identified in this study, including secretogranin II, GluA1, neurofilament, synaptotagmin IV, Nr4a1, and Nr4a2 were previously reported to be reduced in AD brains or CSF (Wakabayashi et al., 1999; Ginsberg et al., 2000; Marksteiner et al., 2002), whereas others, including BDNF and chromogranin A, are altered and may be novel biomarkers at early AD cognitive stages (Li et al., 2009; Perrin et al., 2011). Similarly, Arc and Nr4a2 were significantly reduced in human hippocampus at intermediate $\mathrm{AD}$ pathological stages. These changes are consistent with a decline of neurotransmission and plasticity genes coinciding with intraneuronal $\mathrm{A} \beta$ at intermediate $\mathrm{AD}$ stages (Bossers et al., 2010). Similarly, Crtc1-dependent gene changes coincided temporally with initial amyloid accumulation and memory deficits in $\mathrm{APP}_{\mathrm{Sw}, \text { Ind }}$ transgenic mice, suggesting a casual link between these events. These transcriptome alterations are likely caused by age-dependent $\mathrm{A} \beta$ accumulation since APP, $\alpha \mathrm{APP}$, or APP CTF are unchanged between 2 and 12 months in $\mathrm{APP}_{\mathrm{Sw} \text {,Ind }}$ transgenic mice. Therefore, we propose that changes on Crtcl-dependent genes related to synaptic function and plasticity are associated with early pathological progression and memory deficits in $\mathrm{AD}$.

Our results indicate that neuronal activity and spatial memory training activate a $\mathrm{Crtc1}$-dependent transcriptional program that includes, among others, genes essential for neurotransmission (Scg2, Syt4, Rab2a, Chga), synaptic plasticity and memory (Arc,
A
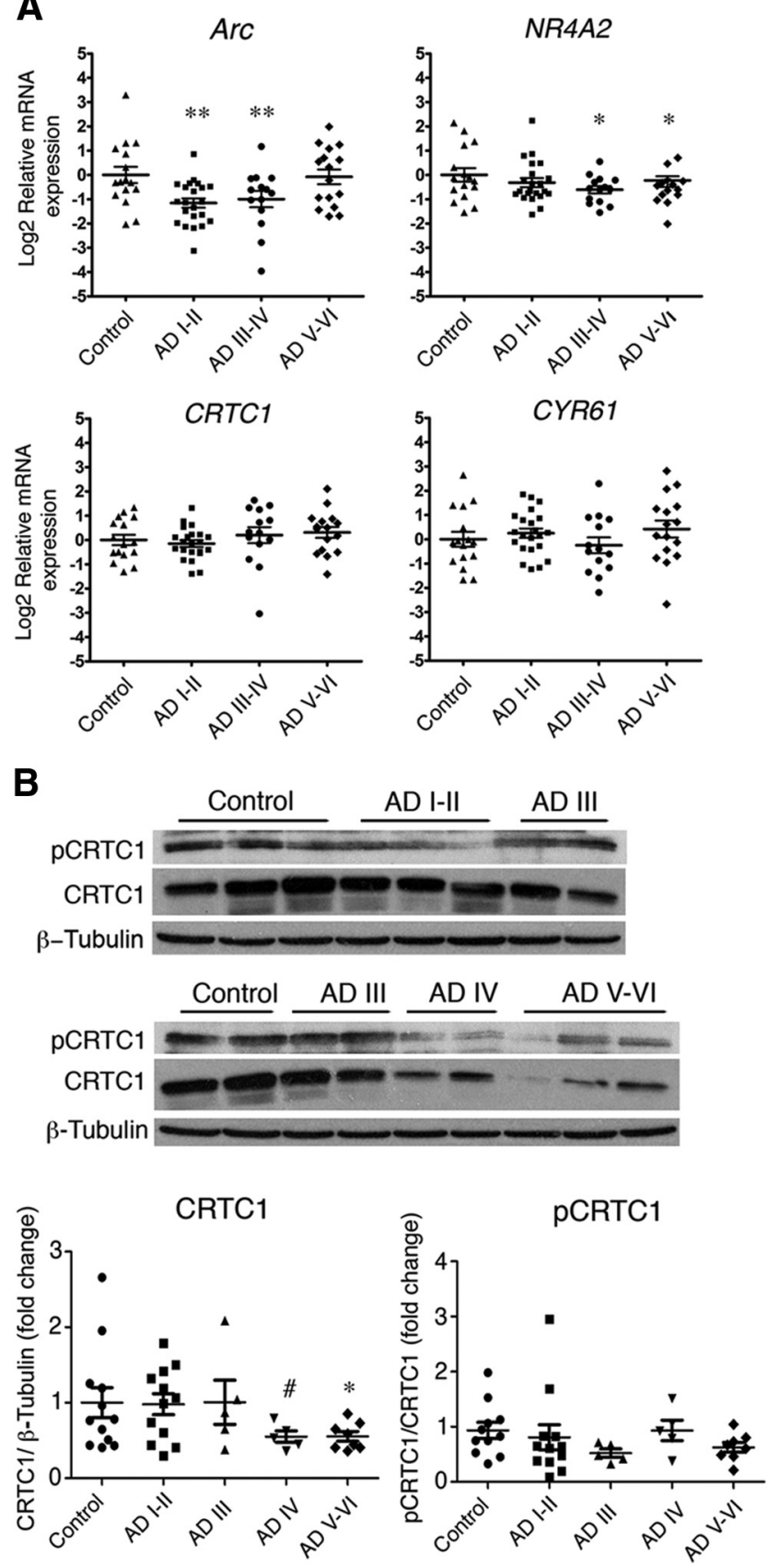

Figure 5. CRTC1 levels and transcriptional changes in human brain at intermediate AD pathological stages. $\boldsymbol{A}$, Levels of ArC, NR4A2, CRTC1, and CYR61 transcripts in the human hippocampus at Braak 0 (Control; $n=16), I-I I(n=22), I I I-I V(n=14)$, and V-VI $(n=16)$ stages. Arc is significantly reduced at early (I-II) and intermediate (III-IV) Braak stages compared with controls $\left(F_{(3,64)}=4.7, p<0.005\right)$, whereas NR4A2 is reduced at intermediate stages. Gene changes in $\log 2$ scale relative to controls are normalized to the geometric mean of PPIA, GAPDH, and $\beta$-actin. Values represent mean $\pm \mathrm{SEM}$; ${ }^{*} p<0.05,{ }^{* *} p<0.02$, compared with controls. $\boldsymbol{B}$, Western blotting and quantification of total and phosphorylated (Ser151) CRTC1 (pCRTC1) in human hippocampus at different AD stages. Values represent mean fold change \pm SEM $(n=$ 5-12 per group); ${ }^{*} p<0.05$ compared with control as determined by one-way ANOVA followed by Scheffé's $S$ post hoc test.

c-fos, Nr4a1, Nr4a2, Bdnf), and neuritogenesis (Nefl). This result agrees with previous reports showing preferential activation of CREB transcriptional programs by neuronal activity and memory training (Guzowski et al., 2001; Benito et al., 2011). It is interesting that Crtcl expression is decreased by sustained neu- 
ronal activity suggesting that a still unknown feedback regulatory mechanism tightly controls Crtc-dependent transcription. The mechanism underlying Crtcl activation involves Crtc1 dephosphorylation at Ser151, a motif that regulates Crtcl nuclear translocation and function (España et al., 2010b; Ch'ng et al., 2012). Crtcl dephosphorylation seems to regulate the induction or maintenance rather than basal CREB-dependent gene expression since efficient recruitment of Crtc1 to specific CREB gene promoters depends on synaptic activity (Fig. $3 F$ ). In addition, Crtc1dependent transcription depends on the specific cellular stimulus and system, which results for instance in modest (0.5- to 4-fold) or high (5- to 100-fold) gene activation by spatial memory or in vitro synaptic stimulation, respectively. Similar to the effect of Crtc1 ShRNA, Nr4a1-2 are reduced by $30-50 \%$ in the hippocampus of $\mathrm{Crtcl}^{-1-}$ mice, an experimental model characterized by emotional changes (Breuillaud et al., 2012). Whether sustained Crtc-dependent transcription in our experimental conditions is due to the remaining $10-20 \%$ Crtc1 expression, the functional redundancy of $\mathrm{Crtc2}$, and/or alternative transcriptional mechanisms need further investigation.

Our findings also provide strong evidence that $\mathrm{Crtc} 1$ dysfunction is associated with hippocampal-dependent transcriptome and memory impairments. First, Crtc1-mediated transcriptional changes are evident in the hippocampus of memory trained but not naive $\mathrm{APP}_{\mathrm{Sw} \text {,Ind }}$ mice, which agrees with the genome-wide transcriptome results showing major gene changes after cognitive stimulation. Second, age-related CREB gene changes are specific for genes dependent on Crtc1, whereas genes activated independently of Crtc1 (Cyr61, Egr1, or Tob1; Ravnskjaer et al., 2007; España et al., 2010b), are unaffected in $\mathrm{APP}_{\mathrm{Sw}, \text { Ind }}$ mice. Although changes in Arc, $c-f o s$, and $\mathrm{Nr} 4 a 1$ were previously observed in APP transgenic mice (Palop et al., 2005; España et al., 2010b), its contribution to memory loss was unclear. Our results showing that Crtcl gene transfer efficiently rescued spatial memory impairments by enhancing the expression of specific subset of Crtc1-dependent genes strongly indicate a role of Crtc1 dysfunction on memory deficits at early AD-related stages. Several mechanisms have been proposed to underlie Crtcl dysfunction in neurons including changes on kinases or phosphatases (i.e., calcineurin), synapse-nuclear translocation, Crtcl acetylation, or CREB glycosylation (España et al., 2010b; Jeong et al., 2012; Rexach et al., 2012; Ch'ng et al., 2012). Our results suggest that impaired Crtc1 dephosphorylation at Ser151 and nuclear translocation in the CA1/CA3 hippocampus may result in Crtc1-dependent transcriptional changes. However, we cannot rule out the possibility that altered Crtcl levels in advanced $\mathrm{AD}$ stages or disrupted activation of CREB might also contribute to CREB transcriptional changes in $\mathrm{AD}$ (Pugazhenthi et al., 2011).

Previous studies showed that pharmacological and genetic activation of CREB signaling ameliorate synaptic and memory deficits in AD transgenic mice (Vitolo et al., 2002; Gong et al., 2004; Smith et al., 2009; Caccamo et al., 2010; Yiu et al., 2011). Similarly, $\mathrm{Crtc1}$ gene transfer reversed early $\mathrm{A} \beta$-induced $\mathrm{Crtc} 1$ transcriptome changes and spatial memory deficits. Notably, enhancing expression of a specific subset of CREB target genes was sufficient to reverse learning and memory deficits in APP mice. By contrast, Crtcl overexpression in vivo did not affect $c$-fos or decreased CREB target genes activated independently of Crtc1, such as Cyr61 and Chga. This differential effect on gene transcription could be due to the preferential binding of $\mathrm{Crtc1} / \mathrm{CREB}$ to specific $\mathrm{Crtc1}$ target promoters (i.e., $\mathrm{Arc}$, $\mathrm{Nr} 4 a 1, \mathrm{Nr} 4 \mathrm{a} 2 \mathrm{.}$. ) in detrimental of Crtc1-independent CREB promoters (Zhang et al., 2005), epigenetic changes caused by binding of Crtc1 to the CBP/CREB complex (Ravnskjaer et al., 2007), and/or a differential timing of RNA polymerase II occupancy over specific promoters and enhancers (Saha et al., 2011). However, spatial learning and memory were similar in WT mice after Crtcl delivery, a result that contrasts with enhancement of contextual memory by Crctl overexpression (Sekeres et al., 2012). This apparent discrepancy could be due to distinct neural circuits involved in these memory tasks (associative vs spatial) and different gene-delivered vectors (Herpes simplex virus vs adeno-associated virus) targeting different neuronal populations. Finally, synapse loss and dysfunction tightly correlates with cognitive decline at initial $\mathrm{AD}$ stages (Terry et al., 1991; Masliah et al., 2001). Because Crtc1 regulates expression of multiple proteins involved in synaptic morphology, function, and plasticity, our results raise the possibility that Crtcl dysfunction underlies synapse dysfunction in $\mathrm{AD}$. In conclusion, targeting specifically Crtcl, instead of affecting globally CREB signaling, can represent a novel therapeutic avenue to ameliorate transcriptome, synaptic, and cognitive changes at early $\mathrm{AD}$ stages.

\section{References}

Altarejos JY, Goebel N, Conkright MD, Inoue H, Xie J, Arias CM, Sawchenko $\mathrm{PE}$, Montminy M (2008) The Creb1 coactivator Crtcl is required for energy balance and fertility. Nat Med 14:1112-1117. CrossRef Medline

Battke F, Symons S, Nieselt K (2010) Mayday: -integrative analytics for expression data. BMC Bioinformatics 11:121. CrossRef Medline

Benito E, Valor LM, Jimenez-Minchan M, Huber W, Barco A (2011) cAMP response element-binding protein is a primary hub of activity-driven neuronal gene expression. J Neurosci 31:18237-18250. CrossRef Medline

Benjamini Y, Hochberg Y (1995) Controlling the false discovery rate: a practical and powerful approach to multiple testing. J R Stat Soc Ser B 57:289-300.

Bindea G, Mlecnik B, Hackl H, Charoentong P, Tosolini M, Kirilovsky A, Fridman WH, Pagès F, Trajanoski Z, Galon J (2009) ClueGO: a cytoscape plug-in to decipher functionally grouped gene ontology and pathway annotation networks. Bioinformatics 25:1091-1093. CrossRef Medline

Blalock EM, Geddes JW, Chen KC, Porter NM, Markesbery WR, Landfield PW (2004) Incipient Alzheimer's disease: microarray correlation analyses reveal major transcriptional and tumor suppressor responses. Proc Natl Acad Sci U S A 101:2173-2178. CrossRef Medline

Bossers K, Wirz KT, Meerhoff GF, Essing AH, van Dongen JW, Houba P, Kruse CG, Verhaagen J, Swaab DF (2010) Concerted changes in transcripts in the prefrontal cortex precede neuropathology in Alzheimer's disease. Brain 133:3699-3723. CrossRef Medline

Braak H, Alafuzoff I, Arzberger T, Kretzschmar H, Del Tredici K (2006) Staging of Alzheimer disease-associated neurofibrillary pathology using paraffin sections and immunocytochemistry. Acta Neuropathol 112:389404. CrossRef Medline

Breuillaud L, Rossetti C, Meylan EM, Mérinat C, Halfon O, Magistretti PJ, Cardinaux JR (2012) Deletion of CREB-regulated transcription coactivator 1 induces pathological aggression, depression-related behaviors, and neuroplasticity genes dysregulation in mice. Biol Psychiatry 72:528536. CrossRef Medline

Caccamo A, Maldonado MA, Bokov AF, Majumder S, Oddo S (2010) CBP gene transfer increases BDNF levels and ameliorates learning and memory deficits in a mouse model of Alzheimer's disease. Proc Natl Acad Sci U S A 107:22687-22692. CrossRef Medline

Ch'ng TH, Uzgil B, Lin P, Avliyakulov NK, O’Dell TJ, Martin KC (2012) Activity-dependent transport of the transcriptional coactivator CRTC1 from synapse to nucleus. Cell 150:207-221. CrossRef Medline

Conkright MD, Guzmán E, Flechner L, Su AI, Hogenesch JB, Montminy M (2003a) Genome-wide analysis of CREB target genes reveals a core promoter requirement for cAMP responsiveness. Mol Cell 11:1101-1108. CrossRef Medline

Conkright MD, Canettieri G, Screaton R, Guzman E, Miraglia L, Hogenesch JB, Montminy M (2003b) TORCs: transducers of regulated CREB activity. Mol Cell 12:413-423. CrossRef Medline

Dahl JA, Collas P (2008) A rapid micro chromatin immunoprecipitation assay (microChIP). Nat Protoc 3:1032-1045. CrossRef Medline

deIpolyi AR, Rankin KP, Mucke L, Miller BL, Gorno-Tempini ML (2007) Spatial cognition and the human navigation network in $\mathrm{AD}$ and MCI. Neurology 69:986-997. CrossRef Medline

Durinck S, Spellman PT, Birney E, Huber W (2009) Mapping identifiers for 
the integration of genomic datasets with the R/bioconductor package biomaRt. Nat Protoc 4:1184-1191. CrossRef Medline

España J, Giménez-Llort L, Valero J, Miñano A, Rábano A, RodriguezAlvarez J, LaFerla FM, Saura CA (2010a) Intraneuronal $\beta$-amyloid accumulation in the amygdala enhances fear and anxiety in Alzheimer's disease transgenic mice. Biol Psychiatry 67:513-521. CrossRef Medline

España J, Valero J, Miñano-Molina AJ, Masgrau R, Martín E, GuardiaLaguarta C, Lleó A, Giménez-Llort L, Rodríguez-Alvarez J, Saura CA (2010b) $\beta$-amyloid disrupts activity-dependent gene transcription required for memory through the CREB coactivator CRTC1. J Neurosci 30:9402-9410. CrossRef Medline

Ginsberg SD, Hemby SE, Lee VM, Eberwine JH, Trojanowski JQ (2000) Expression profile of transcripts in Alzheimer's disease tangle-bearing CA1 neurons. Ann Neurol 48:77-87. CrossRef Medline

Gong B, Vitolo OV, Trinchese F, Liu S, Shelanski M, Arancio O (2004) Persistent improvement in synaptic and cognitive functions in an Alzheimer mouse model after rolipram treatment. J Clin Invest 114:1624-1634. CrossRef Medline

Guzowski JF, Setlow B, Wagner EK, McGaugh JL (2001) Experiencedependent gene expression in the rat hippocampus after spatial learning: a comparison of the immediate-early genes Arc, c-fos, and zif268. J Neurosci 21:5089-5098. Medline

Huang da W, Sherman BT, Lempicki RA (2009) Systematic and integrative analysis of large gene lists using DAVID bioinformatics resources. Nat Protoc 4:44-57.

Jeong H, Cohen DE, Cui L, Supinski A, Savas JN, Mazzulli JR, Yates JR 3rd, Bordone L, Guarente L, Krainc D (2012) Sirtl mediates neuroprotection from mutant huntingtin by activation of the TORC1 and CREB transcriptional pathway. Nat Med 18:159-165. CrossRef Medline

Klein RL, Dayton RD, Tatom JB, Henderson KM, Henning PP (2008) AAV8, 9, $\mathrm{Rh} 10, \mathrm{Rh} 43$ vector gene transfer in the rat brain: effects of serotype, promoter and purification method. Mol Ther 16:89-96. CrossRef Medline

Kovács KA, Steullet P, Steinmann M, Do KQ, Magistretti PJ, Halfon O, Cardinaux JR (2007) TORC1 is a calcium- and cAMP-sensitive coincidence detector involved in hippocampal long-term synaptic plasticity. Proc Natl Acad Sci U S A 104:4700-4705. CrossRef Medline

Laczó J, Andel R, Vlček K, Macoška V, Vyhnálek M, Tolar M, Bojar M, Hort J (2011) Spatial navigation and APOE in amnestic mild cognitive impairment. Neurodegener Dis 8:169-177. CrossRef Medline

Lee YS, Silva AJ (2009) The molecular and cellular biology of enhanced cognition. Nat Rev Neurosci 10:126-140. CrossRef Medline

Li G, Peskind ER, Millard SP, Chi P, Sokal I, Yu CE, Bekris LM, Raskind MA, Galasko DR, Montine TJ (2009) Cerebrospinal fluid concentration of brain-derived neurotrophic factor and cognitive function in nondemented subjects. PLoS ONE 4:e5424. CrossRef Medline

Liang WS, Dunckley T, Beach TG, Grover A, Mastroeni D, Ramsey K, Caselli RJ, Kukull WA, McKeel D, Morris JC, Hulette CM, Schmechel D, Reiman EM, Rogers J, Stephan DA (2010) Neuronal gene expression in nondemented individuals with intermediate Alzheimer's disease neuropathology. Neurobiol Aging 31:549-566. CrossRef Medline

Marksteiner J, Kaufmann WA, Gurka P, Humpel C (2002) Synaptic proteins in Alzheimer's disease. J Mol Neurosci 18:53-63. CrossRef Medline

Masliah E, Mallory M, Alford M, DeTeresa R, Hansen LA, McKeel DW Jr, Morris JC (2001) Altered expression of synaptic proteins occurs early during progression of Alzheimer's disease. Neurology 56:127-129. CrossRef Medline

Moser MB, Moser EI, Forrest E, Andersen P, Morris RG (1995) Spatial learning with a minislab in the dorsal hippocampus. Proc Natl Acad Sci U S A 92:9697-9701. Medline

Mucke L, Masliah E, Yu GQ, Mallory M, Rockenstein EM, Tatsuno G, Hu K, Kholodenko D, Johnson-Wood K, McConlogue L (2000) High-level neuronal expression of $\mathrm{A} \beta_{1-42}$ in wild-type human amyloid protein precursor transgenic mice: synaptotoxicity without plaque formation. J Neurosci 20:4050-4058. Medline

Oddo S, Caccamo A, Shepherd JD, Murphy MP, Golde TE, Kayed R, Metherate R, Mattson MP, Akbari Y, LaFerla FM (2003) Triple-transgenic model of Alzheimer's disease with plaques and tangles: intracellular $\mathrm{A} \beta$ and synaptic dysfunction. Neuron 39:409-421. CrossRef Medline

Palop JJ, Chin J, Bien-Ly N, Massaro C, Yeung BZ, Yu GQ, Mucke L (2005) Vulnerability of dentate granule cells to disruption of Arc expression in human amyloid precursor protein transgenic mice. J Neurosci 25:96869693. CrossRef Medline

Perrin RJ, Craig-Schapiro R, Malone JP, Shah AR, Gilmore P, Davis AE, Roe
CM, Peskind ER, Li G, Galasko DR, Clark CM, Quinn JF, Kaye JA, Morris JC, Holtzman DM, Townsend RR, Fagan AM (2011) Identification and validation of novel cerebrospinal fluid biomarkers for staging early Alzheimer's disease. PLoS ONE 6:e16032. CrossRef Medline

Pugazhenthi S, Wang M, Pham S, Sze CI, Eckman CB (2011) Downregulation of CREB expression in Alzheimer's brain and in $\mathrm{A} \beta$-treated rat hippocampal neurons. Mol Neurodegener 6:60. CrossRef Medline

Ravnskjaer K, Kester H, Liu Y, Zhang X, Lee D, Yates JR 3rd, Montminy M (2007) Cooperative interactions between CBP and TORC2 confer selectivity to CREB target gene expression. EMBO J 26:2880-2889. CrossRef Medline

Rexach JE, Clark PM, Mason DE, Neve RL, Peters EC, Hsieh-Wilson LC (2012) Dynamic O-GlcNAc modification regulates CREB-mediated gene expression and memory formation. Nat Chem Biol 8:253-261. CrossRef Medline

Saha RN, Wissink EM, Bailey ER, Zhao M, Fargo DC, Hwang JY, Daigle KR, Fenn JD, Adelman K, Dudek SM (2011) Rapid activity-induced transcription of Arc and other IEGs relies on poised RNA polymerase II. Nat Neurosci 14:848-856. CrossRef Medline

Saura CA, Valero J (2011) The role of CREB signaling in Alzheimer's disease and other cognitive disorders. Rev Neurosci 22:153-169. CrossRef Medline

Saura CA, Choi SY, Beglopoulos V, Malkani S, Zhang D, Shankaranarayana Rao BS, Chattarji S, Kelleher RJ 3rd, Kandel ER, Duff K, Kirkwood A, Shen J (2004) Loss of presenilin function causes impairments of memory and synaptic plasticity followed by age-dependent neurodegeneration. Neuron 42:23-36. CrossRef Medline

Saura CA, Chen G, Malkani S, Choi SY, Takahashi RH, Zhang D, Gouras GK, Kirkwood A, Morris RG, Shen J (2005) Conditional inactivation of presenilin-1 prevents amyloid accumulation and temporarily rescues contextual and spatial working memory impairments in amyloid precursor protein transgenic mice. J Neurosci 25:6755-6764. CrossRef Medline

Sekeres MJ, Mercaldo V, Richards B, Sargin D, Mahadevan V, Woodin MA, Frankland PW, Josselyn SA (2012) Increasing CRTC1 function in the dentate gyrus during memory formation or reactivation increases memory strength without compromising memory quality. J Neurosci 32 : 17857-17868. CrossRef Medline

Smith DL, Pozueta J, Gong B, Arancio O, Shelanski M (2009) Reversal of long-term dendritic spine alterations in Alzheimer disease models. Proc Natl Acad Sci U S A 106:16877-16882. CrossRef Medline

Smyth GK (2005) Limma: linear models for microarray data. In: Bioinformatics and computational biology solutions using $\mathrm{R}$ and bioconductor, $\mathrm{R}$ (Gentleman R, Carey V, Dudoit S, Irizarry R, Huber W, eds), pp 397-420. New York: Springer.

Terry RD, Masliah E, Salmon DP, Butters N, DeTeresa R, Hill R, Hansen LA, Katzman R (1991) Physical basis of cognitive alterations in Alzheimer's disease: synapse loss is the major correlate of cognitive impairment. Ann Neurol 30:572-580. CrossRef Medline

Thormodsson FR, Redmond L, Hockfield S (1995) Identification of nuclear proteins that are developmentally regulated in embryonic rat brain. J Neurochem 64:1919-1927. Medline

Twine NA, Janitz K, Wilkins MR, Janitz M (2011) Whole transcriptome sequencing reveals gene expression and splicing differences in brain regions affected by Alzheimer's disease. PLoS ONE 6:e16266. CrossRef Medline

Vandesompele J, De Preter K, Pattyn F, Poppe B, Van Roy N, De Paepe A, Speleman F (2002) Accurate normalization of real-time quantitative RT-PCR data by geometric averaging of multiple internal control genes. Genome Biol 3:RESEARCH0034. CrossRef Medline

Vitolo OV, Sant'Angelo A, Costanzo V, Battaglia F, Arancio O, Shelanski M (2002) Amyloid $\beta$-peptide inhibition of the PKA/CREB pathway and long-term potentiation: reversibility by drugs that enhance cAMP signaling. Proc Natl Acad Sci U S A 99:13217-13221. CrossRef Medline

Wakabayashi K, Narisawa-Saito M, Iwakura Y, Arai T, Ikeda K, Takahashi H, Nawa H (1999) Phenotypic down-regulation of glutamate receptor subunit GluR1 in Alzheimer's disease. Neurobiol Aging 20:287-295. CrossRef Medline

Yiu AP, Rashid AJ, Josselyn SA (2011) Increasing CREB function in the CA1 region of dorsal hippocampus rescues the spatial memory deficits in a mouse model of Alzheimer's disease. Neuropsychopharmacology 36: 2169-2186. CrossRef Medline

Zhang X, Odom DT, Koo SH, Conkright MD, Canettieri G, Best J, Chen H, Jenner R, Herbolsheimer E, Jacobsen E, Kadam S, Ecker JR, Emerson B, Hogenesch JB, Unterman T, Young RA, Montminy M (2005) Genomewide analysis of cAMP-response element binding protein occupancy, phosphorylation, and target gene activation in human tissues. Proc Natl Acad Sci U S A 102:4459-4464. CrossRef Medline 